Linköping Studies in Science and Technology

Dissertations No. 1552

\title{
Towards Sustainable Improvement Systems
}

\author{
Dag Swartling
}

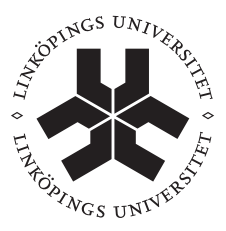

\section{Linköping University}

Department of Management and Engineering Linköping University, SE-581 83 Linköping, Sweden 
(C) Dag Swartling, 2013

"Towards Sustainable Improvement Systems"

Linköping Studies in Science and Technology, Dissertations, No. 1552

ISBN: $978-91-7519-487-5$

ISSN: $0345-7524$

Printed by: LiU-Tryck, Linköping

Distributed by:

Linköping University

Department of Management and Engineering

SE-581 83 Linköping, Sweden

Tel: +4613281000 


\title{
Towards Sustainable Improvement Systems
}

\author{
Dag Swartling
}

\begin{abstract}
$\underline{\text { Abstract }}$
Improvements in general and sustainable improvements in particular are problematic areas. The failure rate is high, figures in the vicinity of 70 percent are often mentioned, but why is it so difficult to achieve sustainable improvement systems? The purpose of this dissertation is to contribute to understanding of the process and its mechanisms in creating a sustainable improvement system. The research questions are:

- What is the process for creating a sustainable improvement system?

- What mechanisms influence the sustainability of improvement systems?

- How do the different mechanisms influence the sustainability of improvement systems?

This dissertation is beyond searching for critical success factors for sustainable improvement systems but rather to identify and investigate mechanisms. Since mechanisms operate within a specific system they are by definition context dependent which critical success factors are not.

The method used to fulfil the purpose was a series of case studies. In total 13 cases has been studied through interviews, participating in meetings, working in the organisation and shadowing.

The research showed that there are major differences between different organisations in how they achieve a sustainable improvement system, despite this it was possible to a build a generic model. The model consists of three phases and three states.

The phases are initiation-transition-sustain. Each phase has a certain state that need to be reached before the next phase can start. The first state which is the outcome of the first phase is that the employees regard the changes as beneficial for them. The second state is that the employees have changed their thinking and behaviour and the third state is that the improvement system is sustainable.
\end{abstract}

Division of Quality Technology and Management

Department of Management and Engineering

Linköping University, SE-581 83 Linköping, Sweden

ISBN: 978-91-7519-487-5

ISSN 0345-7524 


\title{
Towards Sustainable Improvement Systems
}

\author{
Dag Swartling
}

\section{Sammanfattning}

Förbättringar i allmänhet och uthålliga förbättringar i synnerhet är problematiska områden. Andelen misslyckanden är hög, siffror kring 70 procent nämns ofta, men varför är det svårt att uppnå långsiktigt uthålliga förbättringar och förbättringssystem? Syftet med denna avhandling är att bidra till förståelse av processen för att skapa långsiktigt uthålliga förbättringssystem. Forskningsfrågorna är:

- Vilken är processen för att skapa ett uthålligt förbättringssystem?

- Vilka mekanismer påverkar uthålligheten hos förbättringssystem?

- Hur påverkar de olika mekanismerna förbättringssystemens uthållighet?

Denna avhandling går bortom att söka efter kritiska framgångsfaktorer för långsiktigt uthålliga förbättringssystem utan identifierar och undersöker mekanismer. Eftersom mekanismer verkar i ett specifikt system är de definitionsmässigt kontextuella vilket kritiska framgångsfaktorer inte är.

Metoden som använts för att uppfylla syftet är en serie fallstudier. Totalt 13 fall har studerats genom intervjuer, deltagande i möten, arbete i organisationen och skuggning.

Avhandlingen visar att det finns stora skillnader mellan hur olika organisationer uppnår långsiktigt uthålliga förbättringssystem, trots detta var det möjligt att bygga en generell modell, denna består av tre faser och tre tillstånd. Faserna är initiering överföring uthållighet. Varje fas har ett speciellt tillstånd som behöver uppnås innan nästa fas kan börja. Det första tillståndet är att de anställda ser förbättringarna som positiva för dem. Det andra tillståndet är att de anställda har förändrat sitt tankesätt och beteende. Det tredje tillståndet är ett uthålligt förbättringssystem.

Avdelningen för Kvalitetsutveckling Institutionen för Ekonomisk och Industriell Utveckling Linköpings Universitet, SE-581 83 Linköping, Sweden

ISBN: 978-91-7519-487-5

ISSN 0345-7524 


\section{Acknowledgements}

This thesis is the result of several persons effort for a long period of time. First of all I would like to thank my supervisors Professor Lars Witell and Associate Professor Bozena Poksinska for their never ending patience and energy when reading long manuscripts. Henrik Kock deserves a special thank for reading and commenting on an earlier version of this thesis. I would also like to thank Vinnova for funding the research. Among my colleagues I would especially like to thank Promporn Wangwacharakul for helping me with the layout. Apart from her I would like to thank all individuals that have helped me in my professional development at Linköping University. So thank you (in alphabetical order) Anna, Christian, Christina Ö, Filiz, Jörgen J, Mattias, Nicolette, Peter, Rune, and Thomas. Apart from that I would like to thank the colleagues at PIE, Q, other PhD students at IEI, and Juhani for their contribution to the social climate.

In my private life would like to thank my mother for all support during the years.

I would also like to thank Lina for support, although she thinks I am a Tonto, and Tiina for co-operation with the youths, Sebastian and Noomie whom I would like to thank for making my life much more interesting

Linköping 20131021

Dag Swartling 



\section{Appended Papers}

I Dag Swartling

"Two views on Lean production: Alternative interpretations of the Toyota production system"

This paper is currently in the second round of the review process for an academic journal. Empirical data for this paper has been collected from four organizations, in two of these organizations data was collected jointly by Swartling and Poksinska. All other work was done by Swartling.

\section{Dag Swartling, Daniel Olausson}

"Continuous improvement put into practice - Alternative approaches to getting a successful quality programme", International Journal of Quality and Service Sciences, Volume: 3 Issue: 3 2011, (pp. 337 - 351)

Data collection for this paper was done jointly by Olausson and Swartling. Analysis and a major part of the writing was done by Swartling.

III Dag Swartling, Bozena Poksinska

"Management initiation of continuous improvement from a motivational perspective", Journal of Applied Economics and Business Research JAEBR, 3 (2): 81-94 (2013)

Empirical data for this paper was collected jointly by Poksinska and Swartling. Analysis and main part of the writing was done by Swartling

IV Bozena Poksinska, Dag Swartling, Lars Witell

"From Successful to Sustainable Lean Production - The Case of a Lean Prize Award Winner"

This paper is a late manuscript and there is currently ongoing work. Empirical data for this paper was collected jointly, mostly by Swartling and Poksinska, but also to some extent by Drotz. Writing was done jointly by Swartling, Poksinska and Witell with Poksinska taking the main responsibility. 
"Changing the thinking and behaviour of an individual when implementing Lean production"

Empirical data for this paper was collected mostly by Swartling, but support both in data collection as well as analysis and writing was given by Poksinska.

VI Bozena Poksinska, Dag Swartling \& Erik Drotz

"The daily work of Lean leaders - lessons from manufacturing and healthcare", Total Quality Management \& Business Excellence, Volume 24, Issue 7-8, August 2013, pages 886898

Empirical data for this paper was collected jointly, mostly by Swartling and Poksinska, but also to some extent by Drotz. Writing and analysis was done jointly by Swartling, Poksinska and Drotz with Poksinska taking the main responsibility. 


\section{Additional Publications}

Swartling D., Andersson L. (1997) Omdaningen - Systematiskt förändringsarbete i produktionen, IVF-skrift 97855, Göteborg Sweden

Granfors-Wellemets U., Lundin R., Swartling D. (1998) Technology driven change fail or succeed - Case studies of 24 Swedish companies In the proceedings of International Conference Q-ERGO Linköping Sweden

Aresu E., Swartling D., Bellgran M., Herbertsson J. ((1999), Potentials for Improvements in Integrated Development of Products and Production Systems at 19 Swedish companies in the proceedings of International conference Managing Enterprises 99, Brisbane Australia

Swartling D., Sigemyr T. (2003), Improve your company-but in what area A method that pinpoints improvement area related to company strategy, In the proceedings of International conference EUROMA- POMS 2003, Como Italy

Swartling D. (2004) To involve or not to involve - A literature study concerning supplier involvement during new product development In the proceedings of International conference IPSERA 2004, Catania Italy

Swartling D. (2005), Insourcing av produktionen- Erfarenheter från sex företag, I Alternativ till Outsourcing Liber Malmö

Swartling, D. (2007), Learning and Production Improvements, Department of management and engineering, Project Management, Innovations and Entrepreneurship Linköping University, Linköping Studies in Science and Technology. Thesis, ISSN 0280-7971; 1316

Linköping Linköpings universitet

Swartling D. (2010) Missing Link Between change approaches, In the proceedings of the International conference QMOD in Verona 2010 



\section{Content}

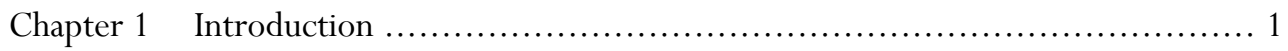

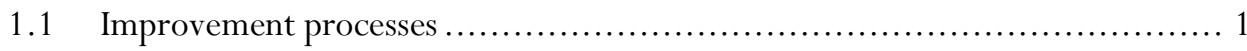

1.2 Mechanisms behind sustainable improvement systems ........................ 3

1.3 Purpose and research questions .......................................... 3

Chapter 2 Theoretical framework ….......................................... 5

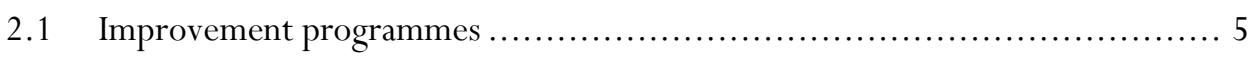

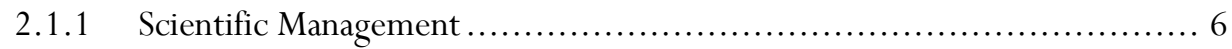

2.1.2 Human Relations.................................................... 7

2.1.3 The Quality Movement .............................................. 8

2.1.4 Lean Production ..................................................... 10

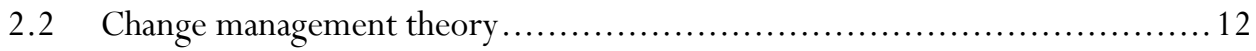

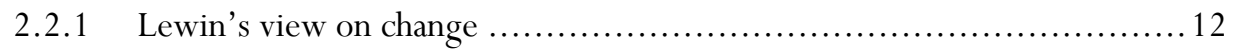

2.2.2 Change as act of management and change agents.......................... 13

2.2.3 Alternative change management theory ................................ 14

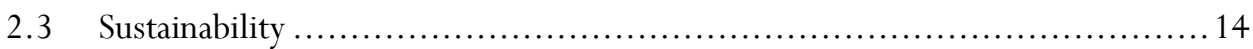

2.3.1 Work-focused motivational theory …................................. 16

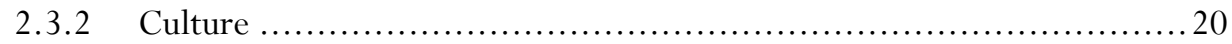

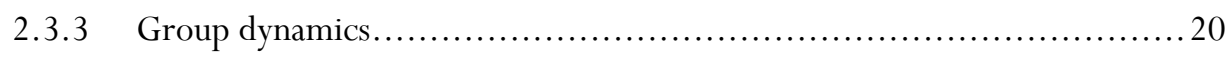

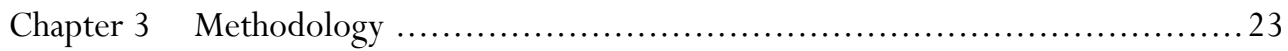

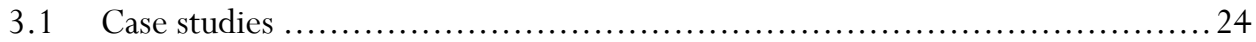

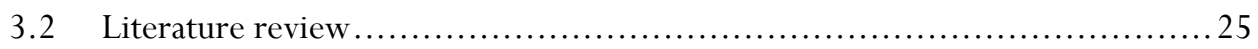

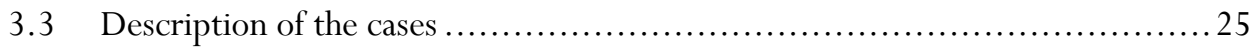

3.4 Different types of data collection............................................. 29 


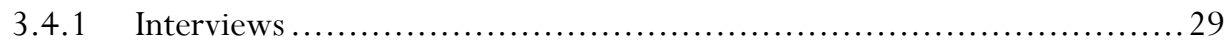

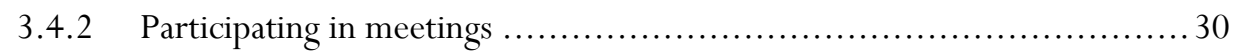

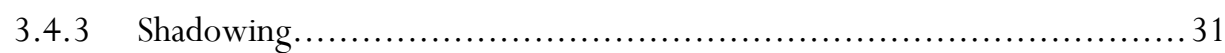

3.4.4 Working on the workshop floor .................................. 31

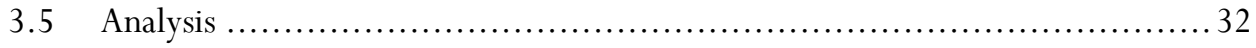

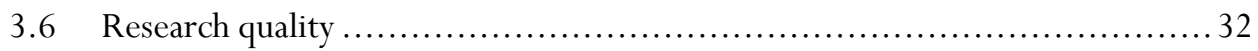

Chapter 4 Description of papers ......................................... 35

4.1 Two views on Lean Production.......................................... 36

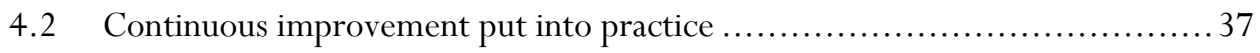

4.3 Motivational issues when initiating CI ............................... 37

4.4 From successful to sustainable Lean.................................... 38

4.5 Changing thinking and behaviour..................................... 39

4.6 The daily work of Lean leaders ...................................... 39

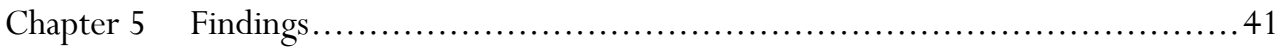

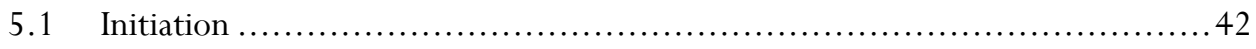

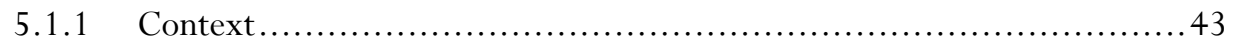

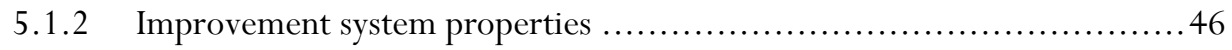

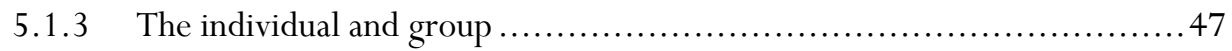

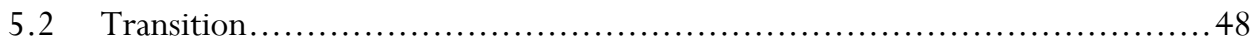

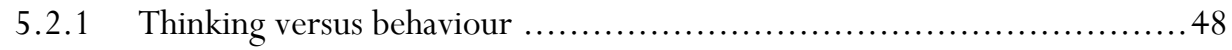

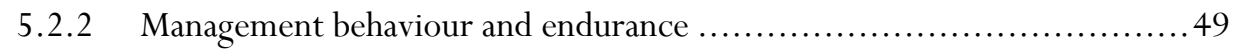

5.2.3 Forces affecting the individual .................................. 50

5.2.4 The role of systems, methods and tools........................... 51

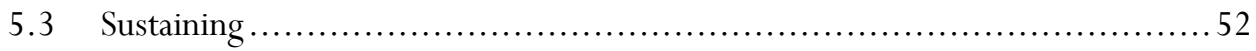

Chapter 6 Conclusions and contribution..................................... 55 


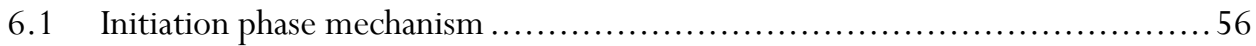

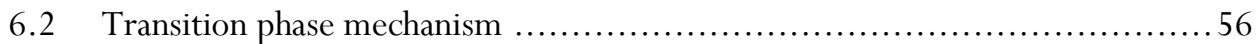

6.3 Sustain mechanism ..................................................... 58

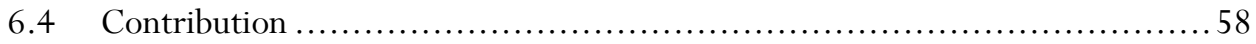

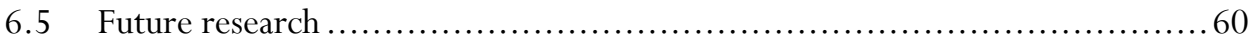

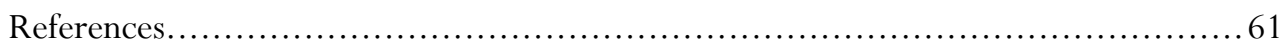

Appendix I Template used for observations during meetings 



\section{Chapter 1 Introduction}

In the summer of 1998, Malmstens AB, a small supplier company in Ljungby, Sweden, was on the verge of being closed down. It had lost money for six consecutive years and the owners issued an ultimatum: profit within six months, or we will close the factory. Six months later, billing had increased 30 percent and the company was profitable. A newspaper wrote an article about the turnaround with the heading, "Stubborn consultant turns loss into profit" (Lindholm, 2000). The stubborn consultant was me. The case was notable in that it was successful both in the short term and the long term. The company has not only survived, but recently added employees. At Malmstens AB they questioned their behaviour and thinking and worked toward being better each day.

Though the "stubborn consultant" has since been replaced by the "stubborn researcher", my interest in improvement persists, with the focus having shifted from finding new possibilities to increasing the understanding of mechanisms behind sustainable improvement systems. In particular, my focus has shifted to improvement systems based on Lean Production.

\section{$1.1 \quad$ Improvement processes}

Improvement processes consist of different stages, such as, for example, plan, do, check, and, act (Deming, 1994). At Malmstens, I investigated what needed to be done and did the planning, while the site manager did the actual improvements and the group executive board carried out the "check and act". After I left Malmstens, the site manager continued to search for further improvements and, hence, both planned and carried out improvement work. A reiteration of this series of acts constitutes at least a rudimentary improvement system.

An improvement system takes inputs in terms of for instance problems and opportunities for improvements, and produces an appropriate output, such as increased quality which will reduce costs (Deming, 1991), or less waste which will imply more satisfied 
customers (Liker, 2004). How the improvement system is organised will affect both resource usage and performance (Swartling and Olausson, 2011). An improvement system can either be developed within an organisation, or be based on an existing improvement program; that is, a ready-to-use set of philosophies and tools designed to discover opportunities for and realize improvements. An improvement program consists of both methods and tools and a philosophic superstructure that point out what to improve and why these specific areas are important. Over the years, there have been many improvement programmes, such as Scientific Management (Taylor, 1911), Human Relations (Mayo, 1933), Business Process Reengineering (Hammer and Champy, 1993), Total Quality Management (Dale et al., 2007) and Lean Production (Liker, 2004); a selection of improvement programs will be described in paragraph 2.1. These programmes were developed during different eras; most have had their peak and subsequent decline, frequently due to lack of sustainability.

Hammer and Champy (1993) estimated that between 50 and 70 percent of business improvement systems fail. In addition, Harari (1993) showed that between 67 percent and 80 percent of US and Europe Total Quality Management programmes have failed. Beer (2000) argued that approximately 70 percent of all change initiatives fail. The figure of 70 percent has been questioned (Hughes, 2011); regardless of the figure, it is clear that achieving sustainable improvement systems (SISs) are problematic. In light of the high failure rate there need to be areas within SISs that are not fully understood. (Todnem By, 2005). It seems to be more interesting to perform research on new improvement programmes or invent your own than search for reasons why the old improvement programme did not meet expectations (Buchanan et al., 2005). There are two peculiarities when it comes to improvement programmes: first, they frequently "borrow" tools from each other (Näslund, 2008). For instance, Continuous Improvement (CI) is seen as a part of both TQM and Lean while, when reading the main book on kaizen, TQM suddenly appears as a part of kaizen (or CI) (Imai, 1986). Second, the different programmes rise in popularity and when showing lack of result they fade away just to be superseded by the next generation improvement programme that to a great extent consists of the same tools (Näslund, 2008). Different organisations that did not quite succeed with the earlier improvement programme can try out the new one, with the result of this new effort will strangely in most cases not be better then last time or the time before that. Jumping between different improvement programs will produce results in terms of used resources and change programme fatigue among employees, but not much else (Swartling and Olausson, 2011).

To understand the mechanisms behind SIS is important to retain competitive strength. This understanding will be built step by step throughout the rest of the dissertation. 


\subsection{Mechanisms behind sustainable improvement systems}

Though there has been a lot of research aimed at establishing change success factors (Todnem By, 2005), it is doubtful that there can be a generic change concept with certain success factors.

"There are many dangers with searching for key ingredients for success and then making prescriptions about what management should do in other organisations. Such approaches neglect the dynamic nature of change.... A successful change recipe cannot be transferred to different contexts, however well it is 'spun' by gurus and consultants".

(Hughes, 2006 p.4)

Instead of trying to establish generic critical success factors, this dissertation will focus on mechanisms. A mechanism is a special way of getting something done within a particular system (Sinclair, 2009). In this dissertation, "something" is the building of a sustainable improvement system (SIS); the system is a particular organisation or part of an organisation. A mechanism, then, describes how different factors interact in order to build an SIS. Mechanisms are not universal, but system-dependent, properties of the system will be described in paragraph 5.1.1 "Context" and, to some extent in 5.2, "Transition".

Sustainability is also a vital element in this dissertation. Sustainability is when changes and change systems survive and develop over time instead of deteriorate and vanish. Sustainability is divided into two orders: the first applies to system-created improvements, and the second to the improvement of systems themselves (Poksinska et al., 2011). Sustainability is influenced by combinations of a multiple of factors such as leadership, organisation, culture, politics, context and timing; some of these are beyond direct management control and there is no simple prescription for managing sustainability (Buchanan et al., 2005); the different factors will be described in more detail in chapter 5. There is also a range of links between the different factors. Since it is not the factors themselves, but rather in a system depending combining that impacts the outcome, it is preferable to talk about mechanisms. The SIS mechanisms are described in chapter 6 .

\subsection{Purpose and research questions}

It is time to stop looking for excuses and instead find ways to make improvements last but as earlier mentioned, in order to do this, there need to be an understanding of the mechanisms behind improvement systems that deliver results both in the short and long term. The purpose of this dissertation is to contribute to understanding of the process and its mechanisms in creating a sustainable improvement system. The research questions are:

- What is the process for creating an Sustainable Improvement System?

- What mechanisms influence the sustainability of improvement systems? 
- How do the different mechanisms influence the sustainability of improvement systems?

As indicated in the introduction and further strengthened by the research questions, this dissertation abjures searching for critical success factors for investigating contextdependent mechanisms. Since mechanisms operate within a specific system they are by definition context dependent which critical success factors are not. 


\section{Chapter 2 Theoretical framework}

The choice of which theories to include and what theories to exclude is troublesome. In this dissertation, the theoretical framework has been based on two thoughts. First, there is the progression of more or less historical improvement programmes; that is, scientific management, human relations, and the quality movement leading up to Lean production. The second is to describe theories that have been shown useful within the research. Those theories are divided into change management theory and theory concerning sustainability.

Change management theory starts with the classic works of Lewin $(1947,1948)$ that are still influential. Since this dissertation questions the view that improvement systems are only a matter of change agents and management actions, pertinent theories are presented. In addition, alternative change management theories are presented.

Sustainability is described in the final part of the theoretical framework. The National Health Service (NHS) definition of sustainability implicitly guides the choice of theories to be described toward motivational theory and culture. Group dynamics, which is the final part of the theoretical frame, has emerged as a vital theoretical area during the research process.

Though sustainability has attracted limited research, there is plentiful research on several different improvement programmes with a history that stretches to the beginning of the 20th century. This dissertation builds on existing theory from several different disciplines, and applies an individually centred perspective. In doing this, it creates a deeper understanding regarding the mechanisms behind SISs and some "know why" regarding changes. There is a need for more "know why" since improvement systems is a problematic area and the mechanisms behind SISs have not been fully understood (Porras and Robertson, 1992, Todnem By, 2005).

\subsection{Improvement programmes}

An improvement programme consists of a set of tools combined with a philosophy as described in paragraph 1.1. Historically, different improvement programmes focused on 
different areas. For instance, Scientific Management focused on using scientific methods to establish a fair day's work, while Human Relations focused on individuals' treatment. The reason for the interest in theories that are approximately 100 years old is that organisational science is more connected to Feyerabend's 1975 theory of different paradigms complementing each other than Kuhn's 1970 theory of different paradigms replacing each other. The theory on improvement programmes of today are influenced by past improvement programmes. The tools are as described section 1.2 in many cases taken from one improvement programme and incorporated in the next. Another reason is to show that today's interpretation of these early improvement programmes diverges substantially from what can be found in the original sources. As a consequence, there has been an intention to use old theories collected from the original sources, starting from 1911 and onward.

\subsubsection{Scientific Management}

At the beginning of the 20th century, Frederic Taylor introduced Scientific Management to counter what he saw as an enormous waste:

"We can see our forests vanishing, our water-powers going to waste, our soil being carried by floods into the sea; and the end of our coal and our iron is in sight. But our larger wastes of human effort, which go on every day through such of our acts as are blundering, ill-directed, or inefficient, and which Mr. Roosevelt refers to as a, lack of 'national efficiency,' are less visible, less tangible, and are but vaguely appreciated".

(Taylor, 1911 p. 1)

Scientific Management's basis was that work could be done more efficiently using scientific methods so that each worker could be used to his full potential. It made four different recommendations (Taylor, 1911):

- Develop a science for each work element to replace the old rule-of-thumb method.

- Scientifically select and train the worker (earlier, these tasks were completed by the worker himself).

- Cooperate with the worker to ensure all work is done in accordance with the scientific principles developed.

- Change the work division so that management takes over all work for which it is better fitted than the workers.

Scientific Management prompted drastic productivity improvement, mostly by eliminating soldiering; that is, workers deliberately reducing their pace. Workers benefitted from the productivity improvements by increased salary. One of the novelties proposed by Taylor (1911) was the paced production line.

Taylor proposed a new type of leadership where eight individuals, each an expert in his/her own area, were to jointly lead the workers. This was because Scientific 
Management demanded more expertise than a single supervisor could have to find out exactly how a specific task should be performed and then to monitor that this was being carried out. In this way, Scientific Management was about changing the behaviour of the employees to use a scientifically developed work standard. Taylor explicitly warned about supervisors setting the piece-rate system since the lack of expertise would result in worker-management tension. Ironically, when Scientific Management was put in to practice, it was often performed in a manner that Taylor explicitly advised against (Sköldberg, 1990). The result was strong tension between workers and management and productivity in many cases did not increase as expected. One of the cases where Scientific Management did not meet to expectations was the Western Electric Hawthorne factory outside Chicago where 29,000 employees produced telephone equipment.

\subsubsection{Human Relations}

Human Relations was to some extent a reaction of employees to Scientific Management. In Scientific Management, workers were only to use their muscular power and the only reward system was salary. However, although salaries rose, there was often huge employee turnover, up to 300 percent early on. It seemed as if employees were not looking for increased salary as their only reward.

The beginning of Human Relations was the three Hawthorne lighting experiments that started in November, 1924. The purpose was to investigate the relationship between lighting and industrial efficiency (Dickson and Roethlisberger, 1939). In the first experiment, the standard production rate during normal illumination was established in three departments, followed by increasing illumination in different intervals. The result was diverse. The two following experiments also shoved diverse results. A more structured test followed in 1927 that involved five relay assemblers being put in a room with a special observer to conduct illumination and pause experiments in a controlled environment. Four of the five female workers were 20-21 years old at the start of the experiment and had Polish parents; the fifth worker was 29 and from Norway. In the factory, there was harsh supervision, but in the test room there was quite another tone that recognised that the women formed a social group. The observer kept accurate records of all that happened and created and maintained a friendly atmosphere in the test room (Dickson and Roethlisberger, 1939).

The women were asked not to work extra hard. Despite this, production rates increased constantly, regardless of changes in illumination or pauses. The increases showed a similar pattern for operators 1 and 2 and for operators 3 and 4; the pattern for operator 5 was different from both other groups. After 39 weeks, both operators 1 and 2, having talked too much during work, were replaced by operators $1+$ and $2+$. They were both in their early 20s; operator $1+$ had Polish parents and operator $2+$ had Italian parents. The productivity continued to rise, despite using test periods with up to 15 percent working hour reductions. Five potential explanations were introduced to explain the phenomenon: 
1. Improved working environment, since a fan had been installed in the room

2. Reduced fatigue: if the workers initially had a lot of accumulated fatigue, then its reduction could explain the increased production

3. Reduced monotony through introducing breaks and working hour changes

4. Increased incentives, since salary was based on a group piece-rate system

5. Changed managerial circumstances.

All explanations were rigorously tested and only the fifth could not be rejected. Eventually, there was a steady stream of visitors, consultants, industrialists, experts on industrial relations, industrial physiologists and university physiologists to the test site. The inspection section manager also made frequent visits and was very interested in the experiment. The social situation included not only the external events, but also the individual meanings allocated to them; the working condition changes had affected the social meaning rather than the physical circumstances (Dickson and Roethlisberger, 1939). Over the years, the notion has become widespread that the Hawthorne experiments were only about illumination changes and that the high level of external interest explained the increased production rates; this interpretation is far from correct (Sköldberg, 1990).

To further complicate the picture, another experiment was performed, the design of which was similar to the relay assembly experiments. In this experiment, the operators were working with splitting mica. Although the same changes were made, the result was not the same; there was even reduced productivity when there were rumours that the mica splitting was to be moved to another factory. The main difference between the experiments was that in the former, the individuals formed a group, while in the latter, the participants remained individuals (Dickson and Roethlisberger, 1939). The main conclusions from the Human Relations improvement programme were the following:

- People are emotional, rather than rational, beings, and their emotional and social needs can have more influence on their behaviour than financial incentives.

- Organisations are cooperative social systems, and people seek to meet their emotional needs through forming informal workplace groups.

- While organisations consist of formal practices and procedures, there is also an informal structure with its own rules and norms (Mayo, 1933).

The contribution from Human Relations was a change in how employees were seen, within Scientific Management the employees were only cogs in the machinery wanting more money while within Human Relations the employees were seen as social creatures with needs for more than money. Human Relations also contributed with clarifying the existence and to some extent function of the informal organisation.

\subsubsection{The Quality Movement}

Among the more known definitions of quality are conformance to requirements (Crosby, 1979), and fitness for use (Juran, 1989). Shewhart (1931) stressed that there are two 
different quality dimensions: one is that it is connected to a specific objective reality independent of people, while the other concerns how individuals feel or sense when exposed to this actual reality. Quality is, thus, both measurable and objective, yet, at the same time, subjective depending on the user. Since the same product can give different quality experiences for different users, the Shewhart definition makes sense. The Quality Movement was based on three main principles: the first was instead of optimising parts of the system, there should be a focus on optimising the whole system toward a common aim (Deming, 1994). The second was to produce correct products since it is more expensive to produce inferior quality. Additionally, inferior products use resources when they are reworked. The third was to have an understanding of natural variation (Deming, 1991).

Other postulates included maintaining processes in statistical balance since changing them will only lead to new problems. More than 90 percent of all quality problems are based on system weaknesses, although operators are often blamed. Improving the system is management's responsibility. Deming established 14 rules on how to achieve quality:

1. Create constancy of purpose toward improving products and services, with the aim to become competitive and to stay in business and to provide jobs.

2. Adopt the new philosophy. We are in a new economic age. Western management must awaken to the challenge, must learn their responsibilities, and take leadership for change.

3. Cease dependence on inspection to achieve quality. Eliminate the need for inspection on a mass basis by building quality into the product in the first place.

4. End the practice of awarding business on the basis of price tag. Instead, minimise total cost. Move toward a single supplier for any one item on a long-term relationship of loyalty and trust.

5. Improve constantly and forever the system of production and service to improve quality and productivity, and thus constantly decrease costs.

6. Institute training on the job.

7. Institute leadership. The aim of supervision should be to help people and machines and gadgets to do a better job. Supervision of management is in need of overhaul, as well as supervision of production workers.

8. Drive out fear so that everyone may work effectively for the company.

9. Break down barriers between departments. People in research, design, sales and production must work as a team to foresee problems of production and usage that may be encountered with the product and service.

10. Eliminate slogans, exhortations and targets for the work force asking for zero defects and new levels of productivity. Such exhortations only create adversarial relationships, as the bulk of the causes of low quality and low productivity belong to the system and, thus, lie beyond the power of the workforce.

11. A. Eliminate work standards (quotas) on the factory floor. Substitute leadership.

B. Eliminate management by objective. Eliminate management by numbers, numerical goals. Substitute leadership. 
12. A. Remove barriers that rob the hourly worker of his right to pride of workmanship. The responsibility of supervisors must be changed from sheer numbers to quality.

B. Remove barriers that rob people in management and in engineering of their right to pride of workmanship. This means, inter alia, abolishment of the annual or merit rating and of management by objective.

13. Institute a vigorous programme of education and self improvement.

14. Put everybody in the company to work to accomplish the transformation. The transformation is everybody's job.

Deming's points were highly influential, both for Total Quality Management (TQM) and Lean Production (Dahlgaard and Dahlgaard-Park, 2006). However, regarding how to make the transition and what mechanisms are involved, the points provide little insight and instead indicate top management agendas (Yusof and Aspinwall, 2000).

The 14 points reveal a strong focus on long-term thinking. The importance of top leadership commitment, or rather top management participation, is also stressed by Crosby (1979), who de-emphasised fire-fighting in favour of working proactively to change the mindset of both managers and employees. Since building a quality culture takes several years, or even decades (Dale et al., 2007), the need for long-term thinking and endurance is shared by most (if not all) of the quality gurus.

Juran (1989), Crosby (1979) and Deming (1991) advocated an infrastructure for all improvement projects and that the improvement projects are to be run individually within the infrastructure. Regarding employee participation, Juran argued that the work force should not be permanent improvement-team members, but rather should participate in quality circles that handle less-complicated departmental problems. Deming had a slightly different view and stated, "the greatest waste in America is failure to use the abilities of people" (p. 53), pointing out that education and individual improvement are essential in all organisations.

\subsubsection{Lean Production}

The term "Lean" was introduced as a new term for Toyota production system (TPS) by Krafcik (1988). Lean was contrasted with "recent Fordism", or buffered production systems. Lean was seen as a development from pure Fordism; that is, the original Henry Ford production system, which, to a high degree, was influenced by Scientific Management. Pure Fordism was introduced in the Rouge River complex in 1913; among the novelties was the moving assembly line, as suggested by Taylor in 1911. The main difference between pure Fordism and TPS was that TPS was far more flexible. Flexibility was needed due to the huge difference in number of produced vehicles (Liker, 2004): in its first 10 years, Toyota's production (93,263 units) was only 11 percent of what Ford produced in 1935 alone. 
TPS has evolved over the years (Liker, 2004, Holweg, 2007), with its definition depending to some extent on when the relevant study was made. "The Machine that Changed the World", one of the best sellers on Lean Production, described the most apparent part of a Lean system, that is, the tools and techniques for eliminating waste. The purpose was not to understand or describe TPS in detail, but to present a benchmark study that showed it to be superior to American or European production systems. Being long term this is important within Lean Production (Liker, 2004). There is a constant striving for an ideal state with no waste and strong employee development (Liker and Convis, 2011).

As described in the introduction, Lean originates from TPS. In the present context, Lean is seen as a philosophy aimed at reducing waste. Lean is based on employee development and empowerment. There are 14 basic principles within Lean (Liker, 2004):

1. Base your management decisions on long-term philosophy, even at the expense of short-term financial goals.

2. Create continuous process flow to bring problems to the surface.

3. Use "pull" systems to avoid overproduction.

4. Level out the workload (heijunka).

5. Build a culture of stopping to fix problems, to get quality right the first time.

6. Standardised tasks are the foundation for continuous improvement and employee empowerment.

7. Use visual controls so no problems are hidden.

8. Use only reliable, thoroughly tested technology that serves your people and processes.

9. Grow leaders who thoroughly understand the work, live the philosophy and teach it to others.

10. Develop exceptional people and teams who follow your company's philosophy.

11. Respect your extended network of partners and suppliers by challenging them and helping them to improve.

12. Go and see for yourself to understand the situation thoroughly (genchi genbutsu).

13. Make decisions slowly by consensus, thoroughly considering all options; implement decisions rapidly.

14. Become a learning organisation through relentless reflection (hansei) and continuous improvement (kaizen).

Many of the 14 Lean principles are related to earlier improvement programmes. Principle 1 is based on the idea that a firm's long-term purpose is to generate value for the customer, society and the economy, not merely to make a profit. Having a long-term focus is also stressed by Deming (1991) and Dale (2007). To always strive in the same direction provides predictability: the employees know the direction of the improvement work, today, next week and next year. Since employees need to change their thinking and behaviour it is problematic to change direction of the improvement work since this would imply a need for another change in thinking. When there is a lack of long-term 
thinking and improvement direction changes with the current fashion, there will be a lack of results, regardless of the amount of resources used (Swartling and Olausson, 2011). Principle 5 is about a change wherein the root cause of the problem is removed, not just fixe the symptom but remove the cause. This principle has a close connection to point 3 of Deming (1991). Principle 9 focuses on leaders and their behaviour. Top management support has been described as a condition for SISs (Bergman and Klefsjö, 2010); leaders focus on developing employees and, therefore, apply theory $\mathrm{Y}$ leadership features (McGregor, 2006). One part of principle 10 is team development; a part of this is group development and group dynamics, which will be described later. Principle 12, to go and see for yourself, is the principle of understanding and solving the real problem, not a conference room model of the problem has motivational impact since solutions that are introduced without proper understanding can appear as if management does not value employee participation. It also increases the suitability of tools or methods used for problem-solving. A solved problem will increase the commitment for change (Repenning, 2002). Finally, Principle 14 is about having an SIS, where everyone participates in improving the organisation.

\subsection{Change management theory}

Since the implementation of an SIS needs to be managed, a small selection of change management theory is included in the theoretical framework.

\subsubsection{Lewin's view on change}

As has been described earlier concerning Scientific Management and Human Relations, there could be differences regarding the original works and how they are interpreted today; this is valid for Lewin as well. Lewin and his work were to a great extent affected by events in his life. He was Jewish and was born in Germany in 1890 in an anti-Jewish atmosphere. Despite difficulties, he managed to get a job as a university teacher.

When Hitler came to power in 1933, Lewin moved to the US, where he wrote papers both on the differences between the US and Germany and on the cultural changes Germany needed after the war as they related to a population that had been indoctrinated by fascist propaganda for their whole youth and adult life. There was also the question of how to change the mindset and behaviour of the people participating in slaughterhouse activities where 6,000-7,000 unwanted women and children were killed daily (Lewin and Lewin, 1948). His conclusions were that things went terribly wrong after World War I due to a laissez-faire leadership style intended to be non-political with earlier potentates still in power but adopting a new role as experts.

This, in combination with tolerance for intolerance, paved the way for the intolerant Nazis' takeover of power. To prevent this from happening again, there was a need for democratic intolerance toward intolerance (Lewin and Lewin, 1948). Lewin suggested addressing the group culture rather than trying to affect individuals due to the number of people (millions) and training democratic leaders and leaders of leaders, which could 
build up a pyramid able to reach large masses of individuals quickly. He also recommended helping the Germans in a cooperative effort to rebuild their country since there were positive experiences after World War I from Americans feeding children all over Germany, die Quaekerspeisung.

As Lewin (1948) described the process of cultural change, values cannot be forced on the individual; rather, the individual must choose the new set of values. What managers or leaders can do is to reduce or delete obstructive forces; that is, make changes more attractive.

Individuals' values are strongly influenced by the groups in which they are a member, although different groups have different influence levels (Lewin, 1947, Lewin and Lewin, 1948). Apart from group influence, there is also the force field model that described how an individual is exposed to different forces that point in different directions. A force originates from a social interaction within a group or dyad. It is more fruitful to decrease the force that resists change than increase the force that promotes change since an increase of the pro-change force is often met by a corresponding increase in anti-change force (Lewin, 1951).

Lewin's planned change model (1951) was individual-centred; individuals and groups were to learn more about themselves and change their behaviour (Burnes, 2009). In the original works by Lewin (1951), the role of group standards and social values were stressed; however, this part of his theory has been lost (Kippenberger, 1998). Today, the most frequently quoted part of the Lewin system is the unfreeze-change-freeze model, that is, unfreezing the present level, moving to the new level, and refreezing to make it permanent. There are variations of the planned process, like the eight-step process of Kotter (1995), or the processes of Deming (1991), or Crosby (1979). They all hold that change is predictable and possible to plan.

\subsubsection{Change as act of management and change agents}

In studies such as Armenakis (1999), or Weick and Quinn (1999), change was seen primarily as a result of change-agent acts. The change agent prepares employees through open and honest communication. Effective communication should address the need for change, the ability to do so successfully, personal valence, existing change support and change strategy appropriateness (Armenakis and Bedeian, 1999). The purpose of the communication is to convert the change recipients to change agents.

Weick and Quinn (1999) divided change into two forms: episodic change, infrequent and discontinuous, and evolving and cumulative continuous change. Both episodic and continuous change emphasise the change agent's role. In episodic change, the agent is the prime mover that creates change; in continuous change, the agent is the sense-maker who redirects change. as well. As Ford et al. (2008) investigated, the change agent also can have a role in building change resistance, a common problem within change programmes and often an excuse when they fail. While recipients can develop change resistance, its 
level is affected by change agent acts. Trust between the change agent and the recipients is vital for changes to occur; acts that violate trust provoke change resistance (Ford et al., 2008). Building trust is a process in which both leaders and followers participate (Klaussner, 2012). Trust is shaped not only by current management or follower actions, but also by previous experiences and organisational contexts (Klaussner, 2012).

\subsubsection{Alternative change management theory}

As a contrast to the above, Pettigrew (1990) stated that sound and useful change research should, "explore the contexts, content, and process of change together with their interconnections through time" (p. 268) and emphasise embeddedness. He differentiated between the outer context, that is, the economic, social, and political environment, and the inner context, that is, the structural, cultural, and political environment. Further, Porras and Robertson (1992) stated that focusing on strategy, structure, processes and culture is not enough to achieve meaningful and lasting change. Although Porras and Robertson also represented the change agent perspective, they pointed out that understanding the variables that influence individuals in a change situation is paramount. They called these variables "organisational work settings" and structured them into four broad categories: social factors, organising arrangements, physical setting and technology. Change programmes alter factors in the work setting, which in turn shape and guide individuals' behaviour on the job.

Yusof (2000) classified the frameworks for implementing TQM into "consultants/experts", "award-based" and "academic-based". Among the "consultants/experts" frameworks, there are Deming's 14 points, Crosby's 14-step quality improvement programme and Juran's 12-step programme. Though there are others as well, all "consultants/experts" frameworks contain steps to follow with limited situational adaption. The "award-based" frameworks typically provide information on the gaps in different areas, but little information on how to close them. The "academic-based" frameworks incorporate step-by-step examples (Oakland, 1993), as well as more holistic views (Dale et al., 2007). Although there are descriptions of how to perform changes step-by-step, benefits are limited by their not following specific patterns (Hughes, 2006). Since changes are meant to affect individual behaviour and thinking, this should be reflected in their process. This process has different starting points depending on how individuals currently behave and think; thus there is a need for adaption. It is unlikely that a generalised set of change injunctions or recipes would fit all organisations; each set needs to be based in a detailed description of content, purpose and change elements (du Gay and Vikkelsø, 2012).

\subsection{Sustainability}

An SIS is a system that is operational for a period appropriate to the setting (Buchanan et al., 2005). Improvement systems unfortunately often decay (Buchanan et al., 1999) due to issues such as the "improvement evaporation effect" when new practices are abandoned (Buchanan et al., 2005), or the "small changes effect" (Hackman and Oldham, 1980), 
where the improvements eventually regress. The NHS Modernisation Agency defines sustainability thusly:

Sustainability is when the new ways of working and improved outcomes become the norm. Not only have the outcome and processes changed, but the thinking and attitudes behind them are fundamentally altered and the systems surrounding them are transferred in support. In other words, it has become an integrated or mainstream way of working rather than something "added on". As a result, when you look at the process or outcome one year from now or longer, you can see that at a minimum it has not reverted to the old way or old level of performance. Further, it has been able to withstand challenge and variation; it has evolved alongside other changes in the context, and perhaps has actually continued to improve over time. (2002, p. 12)

The NHS definition starts with behaviour, that new ways of working has become the norm and then expands to thinking, that attitudes and thinking need to be fundamentally altered. The first part thus concerns the employee. This is followed by the surrounding general systems that need to support thinking and behaviour changes. The need for integration with ordinary tasks is stressed and although not explicitly stated this is the first change in thinking, that is, that improving is part of the work. There is a demand for lasting changes and a wish for further improvements. In line with Poksinska et al. (2011) as described in 1.2, sustained changes constitute first-order sustainability while sustained systemic improvement constitutes second-order sustainability is when the improvement system sustain.

In a literature review (Buchanan et al., 2005), more questions than answers were given regarding this situation. A number of categories that different authors had identified as affecting sustainability were recognised; see Table 1 . 
Table 1 Different categories affecting sustainability (Buchanan et al., 2005)

\begin{tabular}{|l|l|}
\hline Category & Outline definition \\
\hline Substantial & Perceived centrality, scale, fit with organisation \\
\hline Individual & Commitment, competencies, emotions, expectations \\
\hline Managerial & Style, approach, preferences, behaviours \\
\hline Financial & Contribution, balance of costs and benefit \\
\hline Leadership & Setting vision, values, purpose, goals, challenges \\
\hline Organisational & Policies, mechanisms, procedures, systems, structures \\
\hline Cultural & Shared beliefs, perceptions, norms, values, priorities \\
\hline Political & Stakeholder and coalition power and influence \\
\hline Processual & Implementation methods, project management structures \\
\hline Contextual & External conditions, stability, threats, wider social norms \\
\hline Temporal & Timing, pacing, flow of events \\
\hline
\end{tabular}

These factors cover a major part of how an organisation is described and since their importance is unclear and probably differs between different organisations, it is more or less impossible to find a simple prescription for how to achieve SISs (Buchanan et al., 2005). Brännmark and Benn (2012) had a much shorter list where only management improvement system goals and implementation design factored into sustainability. Management goals shifted between living up to demands from external customers for things such as an ISO 9000 certification, to, at the other end of the scale, implementing a system to support their quality management work. Concerning implementing the improvement system, enablers include active ownership, professional steering, competent leadership and engaged participants.

Dale et al. (1997) and Dale (2007) developed a TQM sustaining audit tool that categorised the factors that can hinder sustainability into the following five areas:

- Environment

- Management style

- Policies that may be in conflict with TQM

- Organisation structure

- Process of change

Compared to the factors in Table 1, the similarities are management style and change processes and, to some extent, context, which resembles the environment in Dale (2007). However, since TQM change content is already prescribed, the substantial part is lacking as well as the political, temporal and individual components. In general, Buchanan et al.'s factors cover a wider spectrum than the Dale audit tool.

\subsubsection{Work-focused motivational theory}

The NHS definition of sustainability stresses both behaviour and thinking change. This will not appear spontaneously; there needs to be a reason to change. As will be described 
later, this is a complex phenomenon including a range of factors that form different mechanisms; for the time being, it can be concluded that work-focused motivational theory plays an important role in SISs. Herzberg (1966) used the critical incident method to find reasons for satisfaction and dissatisfaction within the workplace. One set of factors, hygiene factors, results in dissatisfaction, and another set, motivators, results in motivation. Identified factors have different strength and duration. If, for example, hygiene factors are not fulfilled, this will lead to low motivation; however, if they are fulfilled, this does not automatically make them a priori motivational. Herzberg (1966) illustrated this with the example of hearing and seeing: turning the light on will affect your seeing, but not your hearing, and increasing volume will affect hearing, but not seeing. Herzberg did not take into account differences between individuals' hearing and seeing ability; these, among other things, are introduced in the Hackman and Oldham (1980) motivational model. Hackman and Oldham also stressed the need to answer the question "What's in it for me?" as part of introducing changes; at the same time, they argue that there is a bad fit between many employees and their work due to overqualification.

While earlier attempts to increase the fit were focused mainly on the employee, Hackman and Oldham (1980) claimed that the work itself could be redesigned to better fit employees' needs. They developed two measuring tools: Job Diagnostic Survey (JDS), and Job Rating Form (JRF). Using JDS, a specific job's Motivational Potential Score (MPS) can be calculated; using JRF, an individual's Growth Need Strength (GNS) can be calculated.

MPS is calculated as MPS $=1 / 3 *$ (skill variety + task identity + task significance) * autonomy $*$ feedback. Hackman and Oldham also stressed the importance of contextual factors:

What is appropriate in one set of organisational circumstances will wholly miss the mark in another. (1980, p. 67)

Since understanding the organisation is crucial, there are six questions that need to be answered before attempting any change:

1. Is there a problem or exploitable opportunity?

There is a need for a specific problem to be solved or an improvement opportunity. Changes need to be connected to the existing company situation and not stem from a manager hearing about the latest change fashion.

2. Does the problem or opportunity centrally involve employee motivation, satisfaction or work effectiveness?

If the employees are satisfied with their jobs and the quality is good, then there is little to gain from a work redesign. If there are problems, but their reasons stem from causes other than motivation, then work redesign will similarly not contribute to any improvement. 
3. Might the design of the work be responsible for the observed problems? The MPS of the specific work can be calculated; if this is high, then the work design is probably not causing the problems.

4. What aspects of the job most need improvements? MPS consists of five different components. The reasons for low MPS differ among different jobs; therefore, different aspects of the job need to be improved.

5. How ready are the employees for change?

Employee change readiness is described using three different parameters: knowledge and skill, GNS and context satisfaction. Since errors performing different tasks will be more visible in a redesigned work system, knowledge and skill problems will be more apparent. A lack of knowledge and skill can be replaced by a high GNS. If there is dissatisfaction with, for instance, salary, job security or management, then it will make the worker not want to participate in work enrichment. Context dissatisfaction causes are close to the hygiene factors of Herzberg (1966).

6. How amenable are organisational systems to needed changes?

A work area redesign often puts demands on other areas to change as well. When these changes are not possible, the company makes the changes that are possible, which are often safe, feasible, inexpensive and ineffectual.

As indicated above, each job has its own MPS, and each individual has his or her own readiness for change. When combining these sets of parameters, the input variables of the complete job characteristics model appear, see Figure 1. 


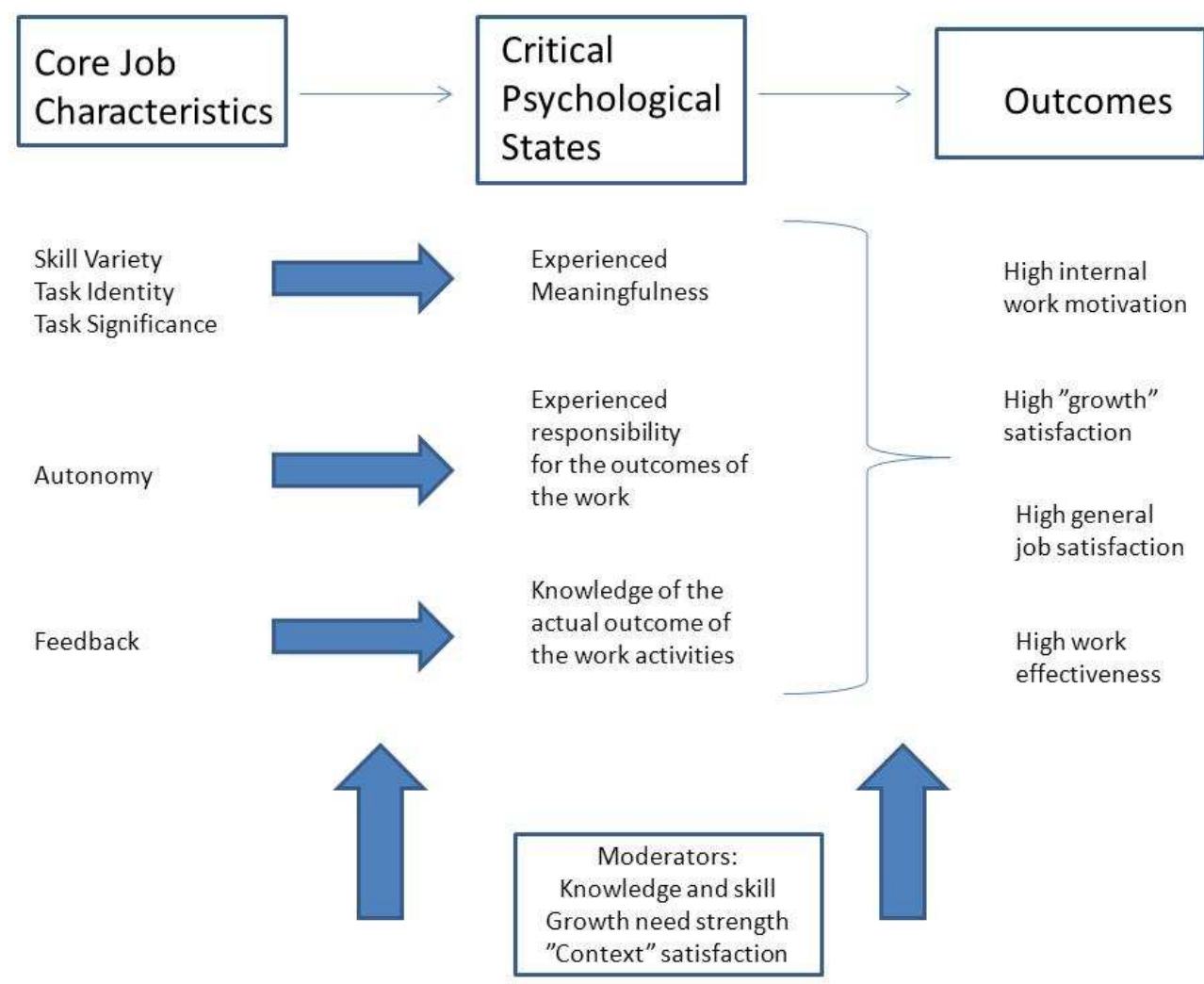

Figure 1 The complete job characteristics model (Hackman and Oldham, 1980)

The core job characteristics affect the critical psychological states, but the strength of the influence is moderated. The critical psychological states affect the outcome, which, once again, is moderated. The high work effectiveness relates more to high quality than high productivity. Since Hackman and Oldham focus on matching the individual and the job, they were not as specific as Herzberg (1966) regarding the influence of different factors. In Larsen et al.'s 2005 model attempting to sum up the different motivation sources (see Figure 2), motivation can also depend on the social situation; this part has been excluded here since this paragraph only covers fork-focused motivational theory. 

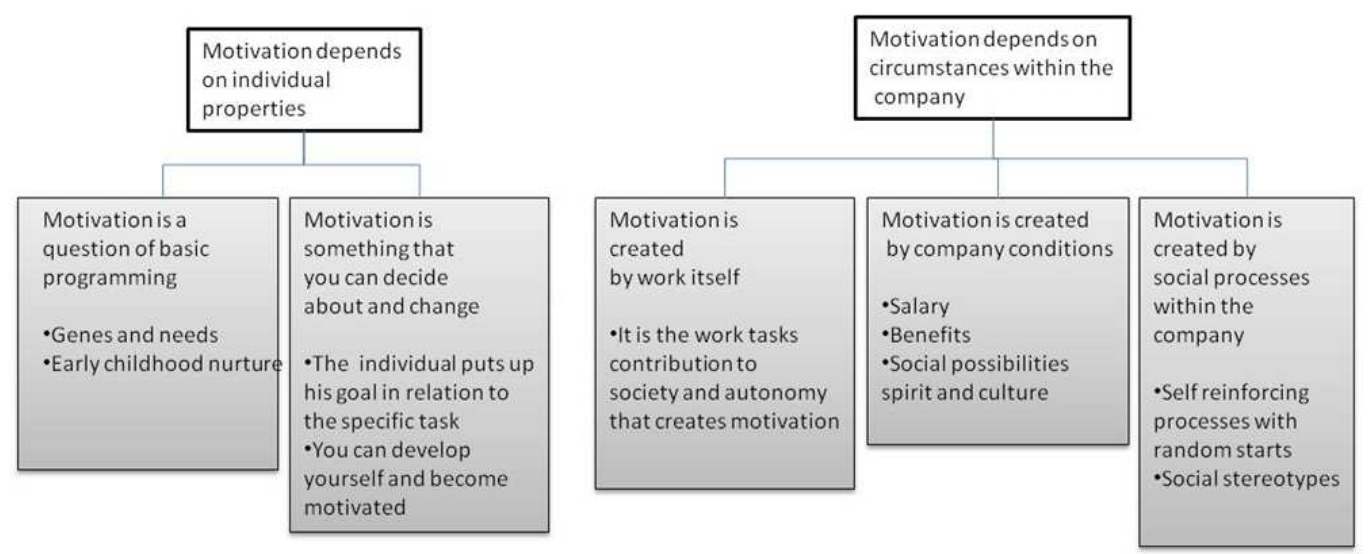

Figure 2 Different sources of motivation (based on Larsen, 2005)

While Herzberg only was interested in the right part of the diagram, Hackman and Oldham also acknowledge individual properties.

\subsubsection{Culture}

Culture influences sustainability (Buchanan et al., 2005), as noted by Dale (2007), who mentions management style as a TQM influence. Leadership is the main force that shapes culture (Schein, 2010); therefore, it directly and indirectly affects improvement system sustainability.

There is inertia in culture: just as earlier management actions have influenced today's culture, so will the actions of today's leaders influence the future culture. Culture can be thought of as the social order foundation and can be divided into three categories: a macro-culture, which covers nations; an organisational culture, which embodies private, public, non-profit and government organisations; and a category that covers different professional subcultures within organisations. A fourth category, micro-culture, refers to a micro-system consisting of several subcultures. within or outside an organisation. (Schein, 2010)

While macro-culture is relatively stable, organisational culture varies between organisations from being more or less absent to a strong guiding principle for all decisions. Subcultures also vary among different groups and micro-culture is the most dynamic kind of culture. The connection between leadership and culture is clearest in organisational and micro-culture; it is not so clear with subcultures.

\subsubsection{Group dynamics}

Whether or not an individual chooses to participate in an improvement system depends on the individual, but also on the properties of the groups to which the individual belongs. Different groups, to a greater or lesser extent, influence how individuals behave and think (Lewin, 1951). Group dynamics' effect on systems is epitomised by the 
Norwegian air traffic controllers' resistance to an improvement initiative (Lofquist, 2011).

All group development models contain different steps in a sequence. The first step is often "belonging" (Wheelan, 1994, Lennéer-Axelson and Thylefors, 2005). Some models have "termination" as the final step, while others lack that step (Maltén, 1992). In this dissertation, Wheelan's model has been chosen since it has the termination step, while its other steps represent most of the models. The Wheelan group development model consists of:

- Dependency and belonging

- Independence and fight

- Trust and structure

- Work

- Termination

In the dependency and belonging step, individuals decide whether or not they want to belong to the group. The independence and fight step consists of asserting different roles in the group; for example, who will be the leader, or what will the hierarchy look like? During this period, there are often pseudo-fights over different issues; although the issue may be solved, the root cause and unclear power distribution remain, giving fuel for new pseudo-fights. During the trust and structure step, norms form, such as how to treat other individuals in the group, or whether it is acceptable to cut off others during discussions or meetings. When norms are set, the group can focus more on work.

In a well-functioning group, the ratio between task and social interaction is in the vicinity of 60/40 percent in favour of task (Wheelan, 1994). In addition, there are roles more focused on different individuals' personae, such as not being engaged in the work (the playboy), always looking for help (help-seeker), or the "monopoly on attention" individual who is very voluble and dominates the group and their meetings (Maltén, 1992, Svedberg, 2003).

A group can get stuck in a step, or there can be instances, such as norm violation, that return groups to previous stages. Since norms guide how individuals behave and, to some extent, how they think (Maltén, 1992, Svedberg, 2003), a change point of view can emphasise group dynamics since it seems to be impossible to predict group behaviour without taking into account group goals, group standards, group values and the way a group compares its own situation to other groups (Lewin, 1951). Although micro-culture describes some of the mechanisms within group dynamics, there is a major difference since culture is described as originating from leaders while group dynamics originate from group members, as was found in the Hawthorne experiments. 



\section{Chapter 3 Methodology}

A distinct methodology is the basis for science (Frankfort-Nachmias and Nachmias, 2007). In order to qualify this work as scientific, it is important to clarify the methodology used. The word "science" originates from the Latin scire, to know. Scientists assume knowledge is tentative and changing; therefore, truth is always relative to the evidence, the methods and the theories employed, and is always subject to modification (Frankfort-Nachmias and Nachmias, 2007). One problem with the changing truth that will be highlighted in the conclusions is that earlier knowledge can be forgotten (Kippenberger, 1998), or misinterpreted (Sköldberg, 1990, Hedegaard Hein, 2012). Knowledge is derived from experience (Frankfort-Nachmias and Nachmias, 2007); this can, in most cases, not be collected only using the five senses and requires points of view and theory.

Academic researchers and management consultants can be seen as knowledge workers that emphasise theory and practice differently: "backed by bits and pieces of theory, the consultant contributes to practice whereas the scholar contributes to theory supported by fragments of practice" (Gummesson, 1999). As described in the introduction, I have worked with organisational changes as a consultant prior to studying them; there were some theoretical bases for the change work performed then, but there was also a lack of theory that, to some extent, was cured when I started to teach organisational change at Linköping University in 2002. From 2002 onward, I performed research in parallel with teaching and presented a conference paper yearly. The subjects covered were insourcing, supplier cooperation within product development, group development, continuous learning in production and identifying improvement areas. Some of these papers formed a licentiate thesis in 2007.

I started as a PhD student in August 2009. This voyage has shaped me in terms of how I see and interpret situations and data. Since I have doubts about true reality and the 
researcher as objective interpreter, it is important to inform the reader about the "glasses" used during the interpretation. During my work as a consultant, on several occasions, I found solutions on the workshop floor and not in the conference room. To me, it is an advantage to get as close to the problem as possible. Naturally, the choice of method depends on the purpose of the study.

This dissertation uses a systematic combining approach in which iterations between theoretical frameworks and empirical fieldworks allow both areas to influence each other (Dubois and Gadde, 2002). There is a need for an initial theoretical understanding, but the theoretical frame is not set during the initial research process. Rather, it evolves based on empirical findings. In this way, systematic combining is close to both the initial theory and the empirical data. Using systematic combining case studies will not be a linear process, but rather an integrated approach where there are no subsequent planned phases. The iteration between theory and data permits deeper understanding.

In this dissertation, the initial precondition was the theory regarding Lean Production and change management. The cases provided a need for deeper analysis invoking motivation theory, internal politics and group dynamics, thus developing theory within SISs.

\subsection{Case studies}

In this dissertation, the prime data source has been case studies. A case study is an empirical investigation that studies a phenomenon in its real-life context. Case studies are especially useful when the boundary between the phenomenon and its context is blurred (Yin, 2003). The choice of possible cases was often hampered by access problems; there were organisations that, although being prime case study candidates, did not want to participate. It is not always the case that the whole organisation is the unit of analysis; it can be a single organisation, a single location, a person or a single event (Bryman and Bell, 2007). In this dissertation, the units of analysis are in all but one case a location; that is, a part of or the whole organisation that shares a location. The only exception is one case where the location consisted of more than 1,000 employees. In roughly half of the cases, the location is part of a bigger organisation; in the other cases, the organisation has a single location.

Case studies can either be single or multiple (Eisenhardt and Graebner, 2007, Yin, 2003). The multiple case or longitudinal case study, has the advantage of offering more possibilities for systematic combination (Dubois and Gadde, 2002), since several data collection instances enable acquiring additional theory. All case studies within this dissertation contain multiple data collection instances. There is one longitudinal single case study and five multiple case studies. The longitudinal single case study provided more depth and the opportunity to study development over time; by contrast, the multiple case studies provided valuable guidance on what theoretical field needed to be studied. Case studies are well suited to answering "how" and "why" questions (Eisenhardt and Graebner, 2007, Yin, 2003) when at least some of the context is what is being studied (Yin, 2003). This dissertation is about understanding a phenomenon that is highly 
context-dependent since the context is, to some extent, what is being studied. This, in combination with the research questions addressing issues of "What" and "How", makes a case study appropriate.

An especially powerful form of case study design is "polar types", where the researcher samples the extremes in order to more easily see data contrasts (Eisenhardt and Graebner, 2007); this approach was used in Paper two. The strategy behind polar case studies is to find examples of cases that are different, identify what the differences are and to establish the causes for these differences.

\subsection{Literature review}

The literature review involved searching for articles in the Web of Science and Scopus databases, as well as Google Scholar. One of the more influential articles is Sugimori et al. (1977), which was the first article to describe TPS. In addition, Lewin (1947, 1948, 1951) provided interesting information, especially on force field theory.

Concerning books, Hackman and Oldham (1980) opened my eyes to motivational theory when I first read it in 1995. More recently, Hedegaard Hein (2012) provided a more balanced view of motivational theory and highlighted original source misinterpretation , an issue also touched on by Sköldberg (1990). This resulted in reading Taylor (1911) to understand the original Scientific Management ideas, which differ substantially from later interpretations (Sköldberg, 1990, Hedegaard Hein, 2012). It also involved reading Dickson and Roethlisberger (1939) and their description of the Hawthorne experiments. This book is a treasure since it describes their empirical data in detail; once again, the common interpretation of the "Hawthorne effect" seems to be mistaken (Sköldberg, 1990).

Regarding group dynamics, Svedberg (2003), Wheelan (1994) and Lennéer-Axelson (2005) have provided useful theories that led to a new interpretation of the Dickson and Roethlisberger data. When researching Lean, it is hard not to mention Liker (2004), although the book is a bit shallow and the lack of references is annoying. The Liker and Meier book (2006) was a true disappointment and showed a lack of consistency; Lean is long term and affects thinking and behaviour, but according to Liker and Meier (2006) it is introduced through a few workshops. Concerning changes, Hughes (2006), Porras and Robertson (1992) and Pettigrew (1993) have been influential, especially in their discussion concerning employees' thinking and behaviour.

\subsection{Description of the cases}

Of the 13 different studied cases, seven provided data for Paper two, while the other six provided data for the other five. As described earlier, Paper two employed polar case studies. The cases are described in tables 2 and 3. The case distribution among the different papers is shown in Table 4. The cases used in all papers except paper two are described below. 
Type Co/Industry operates within the infrastructure sector. In the beginning of this century, it had profitability and reputation problems. Due to internal improvement, as well as increased demand, the situation improved rapidly. However, they have not been able to implement an SIS and have recently been forced to reduce their workforce on several occasions.

The Municipality is a small municipality in the southwest part of Sweden. They had a severe crisis in the mid-1990s, but have since recovered. They worked with basic values so that all employees understood the bases for norms, values and behaviour. The values were used both during recruiting and when choosing improvement methods. They have heavily emphasised a bottom-up approach where all improvement work is initiated, investigated and implemented by the employees; the role of the change agents is taken by those affected by the change. They have deliberately chosen not to build a system for the whole organisation but the improvement system relies on local initiatives. The improvement system is totally bottom up. They have managed to build an SIS for elderly care, but are struggling with building one for high school teachers.

Care Centre 1 is located in the west coast of Sweden. It used to have major problems with stressful work situations. The manager thought that something needed to be done and decided to launch an improvement project with the goals of reducing stress and having fun at work. There was a meeting where all employees gave their views on what was needed to reach the goals. It became evident that they needed to cooperate between different occupational groups and to make things as easy as possible for all personnel involved. There is an SIS that both focuses on making things as easy as possible, but also on reacting to changes in the surrounding conditions.

Care Centre 2 is located in a large city on the east coast of Sweden. It is surrounded by several private care centres and saw a need to better serve its patients. The manager is a personal friend of one of Swedish healthcare's leading Lean individuals who acted as a sounding board for the Care Centre 2 Lean work.

The hospital unit is located in a medium-sized town at the east coast of Sweden. They have improved their efficiency for many years and their reputation has spread. The unit manager is the driving force behind most, if not all, improvement activities.

The department that prepares the substance for the AstraZeneca turbuhaler is located in Södertälje, Sweden. It received the Swedish Lean Prize in 2008. Historically, there was no need to be more effective, since the company was highly profitable due to high margins on top-selling drugs. More recently, there were discussions on relocating to lowwage countries and, subsequently, an increased emphasis on productivity. AstraZeneca started to implement Lean Production in 2002 and has managed to build an SIS.

An overview of the cases is shown in tables 2 and 3. 
Table 2 Description of cases for Papers one, three, four, five and six

\begin{tabular}{|l|l|l|l|}
\hline Case & Description & Bases for choice & $\begin{array}{l}\text { Employees } \\
\text { (Approx. }\end{array}$ \\
\hline $\begin{array}{l}\text { Type Co/ } \\
\text { Industry }\end{array}$ & $\begin{array}{l}\text { Major Swedish actor in } \\
\text { production of a certain type } \\
\text { of energy systems } \\
\text { component. }\end{array}$ & $\begin{array}{l}\text { Has been described in several articles } \\
\text { as a Lean company. }\end{array}$ & 110 \\
\hline Municipality & $\begin{array}{l}\text { A small municipality in the } \\
\text { southwest of Sweden. }\end{array}$ & $\begin{array}{l}\text { Has been presented as a forerunner } \\
\text { among municipalities regarding Lean } \\
\text { Production in an academic } \\
\text { publication, especially in the elderly } \\
\text { care area. }\end{array}$ & 20 \\
\hline Care Centre 1 & $\begin{array}{l}\text { A care centre located in a } \\
\text { small city in the west coast } \\
\text { of Sweden. }\end{array}$ & $\begin{array}{l}\text { Are regarded as a role model for care } \\
\text { centres working with Lean } \\
\text { Production. Have participated in } \\
\text { education for other care centres. }\end{array}$ & 25 \\
\hline Care Centre 2 & $\begin{array}{l}\text { A care centre located in a } \\
\text { big city in the east coast of } \\
\text { Sweden. }\end{array}$ & $\begin{array}{l}\text { Has been presented as one of the most } \\
\text { successful care centres working with } \\
\text { Lean within this particular city. }\end{array}$ & 35 \\
\hline Hospital Unit & $\begin{array}{l}\text { Hospital unit located in a } \\
\text { mid-size city on the east } \\
\text { coast of Sweden. }\end{array}$ & $\begin{array}{l}\text { Has been presented as one of the most } \\
\text { successful hospital units within this } \\
\text { part of Sweden. }\end{array}$ & 20 \\
\hline $\begin{array}{l}\text { Drug } \\
\text { manufacturer/ } \\
\text { AstraZeneca }\end{array}$ & $\begin{array}{l}\text { Drug manufacturer located } \\
\text { in Södertälje. The unit } \\
\text { studied part of the } \\
\text { Turbuhaler manufacturing. }\end{array}$ & $\begin{array}{l}\text { Winner of the Swedish Lean Prize } \\
\text { 2008. }\end{array}$ & 78 \\
\hline
\end{tabular}

As mentioned earlier, Paper two used polar-type cases that represented all four squares of a two-by-two matrix with resource consumption and achieved improvements on the axes. As shown in Table 3, all case organisations were medium-sized with a wide dispersion in business types ranging from metal frames to electronics. Three of the seven companies were within automotive.

Gamma also had connections to automotive since their lifting equipment often is mounted on vehicles. Two of the cases were within the building industry and one within electronics. 
Table 3 Description of cases for Paper two

\begin{tabular}{|l|l|l|l|}
\hline Case & Description & Bases for choice & $\begin{array}{l}\text { Employees } \\
\text { (Approx. }\end{array}$ \\
\hline Alpha & $\begin{array}{l}\text { World's largest producer of a } \\
\text { specific range of motor vehicle } \\
\text { accessories. }\end{array}$ & $\begin{array}{l}\text { Had despite using a lot of resources } \\
\text { not achieved much improvement. }\end{array}$ & 260 \\
\hline Beta & $\begin{array}{l}\text { Large Swedish actor within } \\
\text { metal frames. }\end{array}$ & $\begin{array}{l}\text { Had despite using some resources } \\
\text { only achieved minor improvements. }\end{array}$ & 120 \\
\hline Gamma & $\begin{array}{l}\text { World leading producer of } \\
\text { lifting and material handling } \\
\text { devices. }\end{array}$ & $\begin{array}{l}\text { Had used a lot of resources but at the } \\
\text { same time achieved major } \\
\text { improvements. }\end{array}$ & 250 \\
\hline Delta & $\begin{array}{l}\text { World leading producer of a } \\
\text { specific type of motor vehicle } \\
\text { accessories. }\end{array}$ & $\begin{array}{l}\text { Had used a lot of resources but at the } \\
\text { same time achieved major } \\
\text { improvements. }\end{array}$ & 109 \\
\hline Epsilon & $\begin{array}{l}\text { Global actor within car } \\
\text { industry. }\end{array}$ & $\begin{array}{l}\text { Had despite low use of resources } \\
\text { achieved major improvements. }\end{array}$ & 170 \\
\hline Digamma & $\begin{array}{l}\text { Nordic leader within part of } \\
\text { building industry. }\end{array}$ & $\begin{array}{l}\text { Had despite moderate use of } \\
\text { resources achieved major } \\
\text { improvements. }\end{array}$ & 500 \\
\hline Zeta & $\begin{array}{l}\text { Global actor within electronic } \\
\text { components. }\end{array}$ & $\begin{array}{l}\text { Major improvements combined with } \\
\text { moderate use of resources. }\end{array}$ & 200 \\
\hline
\end{tabular}

Data for the theses was collected from 2009 to 2012, except for Paper two, which was collected in autumn of 2004. The reason for this division of data collection was that the Paper two was originally part of the Licentiate thesis presented in 2007. However, it became clear that this data set had further opportunities. The purpose of Paper two differs widely from the purpose of the paper presented in the Licentiate thesis.

The different cases have been used in the papers according to Table 4. As can be seen from the table, data from the same organisation was used in several papers. Data from AstraZeneca, Municipality and Care Centre 1 was used in four different papers so these cases formed the backbone of the dissertation. Data from Type Co, or Industry which is the same organisation was used in two papers and data from Care Centre 2 and Hospital unit was used in one paper. 
Table 4 Cases used in the different papers

\begin{tabular}{|l|l|}
\hline Paper & Cases used \\
\hline Two views on Lean Production & Type Co, Municipality, Care Centre 1 and Drug manufacturer \\
\hline $\begin{array}{l}\text { Continuous improvement put } \\
\text { in practice }\end{array}$ & Alpha, Beta, Gamma, Delta, Epsilon, Digamma and Zeta \\
\hline $\begin{array}{l}\text { Management initiation of } \\
\text { continuous improvement from } \\
\text { a motivational perspective }\end{array}$ & Municipality, Care Centre 1 and Drug manufacturer \\
\hline $\begin{array}{l}\text { Turning a Successful to a } \\
\text { Sustainable Improvement } \\
\text { Programme: The Case of Lean } \\
\text { Production }\end{array}$ & AstraZeneca \\
\hline $\begin{array}{l}\text { Changing the Thinking and } \\
\text { Behaviour of an individual } \\
\text { When Implementing Lean } \\
\text { Production }\end{array}$ & Type Co./Industry, Care Centre 1 and Municipality \\
\hline $\begin{array}{l}\text { The Daily Round of Lean } \\
\text { Leaders - a Go to Gemba } \\
\text { Study }\end{array}$ & $\begin{array}{l}\text { Drug Manufacturer, Municipality, Care Centres 1 and 2 and Hospital } \\
\text { unit }\end{array}$ \\
\hline
\end{tabular}

\subsection{Different types of data collection}

The main data collection method for this dissertation has been interviews. This was supplemented by participating in meetings, shadowing and working on the workshop floor.

\subsubsection{Interviews}

Semi-structured interviewing is one of the most important methods for data collection within qualitative research (Bryman and Bell, 2007, Yin, 2003). This dissertation is no exception. This type of inquiry depends on methodological considerations made during the interview itself (Kvale and Brinkmann, 2009, Yin, 2003). The more structured the interview, the less need for interviewing experience and craftsmanship (Kvale and Brinkmann, 2009). The interview can be seen as either looking for vital pieces of information hidden within the respondent or creating knowledge through interacting with the respondent (Kvale and Brinkmann, 2009, Bryman and Bell, 2007, Yin, 2003).

The dissertation included 94 interviews. In earlier research projects and in other parts of my work, I have performed about 100 interviews, so it is fair to say that I am an experienced interviewer. The interview focus has been more toward seeking information than interactive knowledge creation, although this has occurred in some instances.

Kvale et al. (2009) described sensitivity as one aspect of a qualitative research interview. One method of increasing sensitivity is to spend time at the workplace where the interviews are to be held (Kvale and Brinkmann, 2009); this was done in two cases. The 
Paper two interviews were focused on improvement work organisation, resource use and results. The focus for all the other papers was understanding how Lean Production was initiated and developed and what its results were both in terms of changed thinking and behaviour and waste reduction. There was also a special focus on leadership. The interview logic was to follow the hierarchical structure within the organisation to target specific managers' subordinates. The interviews were adapted to the individual depending on hierarchical position and, in some cases, length of service as recommended by Bryman and Bell (2007). Table 5 shows a list of the interviews made in the different organisations. The interviews at Type $\mathrm{Co} / \mathrm{The}$ industry were filmed; all other interviews were recorded and transcribed.

Table 5 List of interviews conducted

\begin{tabular}{|l|l|l|}
\hline Case & $\begin{array}{l}\text { No. of } \\
\text { interviews }\end{array}$ & Interviewed \\
\hline $\begin{array}{l}\text { Type Co, } \\
\text { Industry }\end{array}$ & 15 & $\begin{array}{l}\text { production manager, logistics manager, sales manager, quality manager, } \\
\text { lean coordinator, two designers, three supervisors, five operators, plus a } \\
\text { number of spontaneous interviews/ conversations during one week on } \\
\text { the workshop floor }\end{array}$ \\
\hline Municipality & 8 & $\begin{array}{l}\text { one facilitator, one quality manager, two managers for elderly care, four } \\
\text { elderly care employees }\end{array}$ \\
\hline Care Centre 1 & 6 & one manager (doctor), two doctors, three nurses \\
\hline Care Centre 2 & 8 & one manager (physiotherapist), four doctors, two nurses, secretary \\
\hline Hospital unit & 10 & $\begin{array}{l}\text { one manager (doctor), two doctors, one nurse, two secretaries, four } \\
\text { biomedical analysts }\end{array}$ \\
\hline $\begin{array}{l}\text { Drug } \\
\text { manufacturer/ } \\
\text { AstraZeneca }\end{array}$ & 17 & $\begin{array}{l}\text { one factory manager, one production manager, three first line managers, } \\
\text { six operators (2009), one factory manager, one production manager, } \\
\text { two first line managers, two operators (2011), plus a number of } \\
\text { spontaneous interviews/conversations during two days on the workshop } \\
\text { floor }\end{array}$ \\
\hline Alpha & 5 & $\begin{array}{l}\text { design manager, production engineer, two production managers, } \\
\text { operator }\end{array}$ \\
\hline Beta & 3 & design manager, production engineer, production manager \\
\hline Gamma & 4 & production director, two production managers, site manager \\
\hline Delta & 6 & two production managers, two production engineers, two operators \\
\hline Epsilon & 2 & production engineer, production manager \\
\hline Digamma & 5 & $\begin{array}{l}\text { production director, two production engineers, production manager, } \\
\text { operator }\end{array}$ \\
\hline Zeta & 5 & $\begin{array}{l}\text { process and quality engineer, three production manager, production } \\
\text { engineer }\end{array}$ \\
\hline
\end{tabular}

In total, 94 interviews were conducted.

\subsubsection{Participating in meetings}

Participating in meetings were also frequently used for data collection in most cases two researchers participated in the same meeting, using a purpose-designed observation sheet. 
After the meetings, observations were compared and contrasted. When both researchers observed the same meeting and did not interact with the subjects, the extent of difference between the researchers' observations was an indication of reliability, and the discussion afterwards as researcher triangulation. The scheme used during the meetings was based on Elg (2001), and is appended (appendix I). The observation scheme was used at the Drug Manufacturer/AstraZeneca and Care Centre 1.

\subsubsection{Shadowing}

Shadowing in combination with interviews was used to collect data when revisiting AstraZeneca in Södertälje in 2011. Shadowing implies following a person for a longer period, for instance a day, and registering actions and interactions (Czarniawska-Joerges, 2007, McDonald, 2005); it also includes participating in meetings, discussions and daily work (McDonald, 2005). One of the benefits of shadowing is that it provides more detailed data than many other approaches. The technique's pioneers stressed alienation; that is, that the researcher should shadow someone different from themselves as it would provide a more outsider point of view (Czarniawska-Joerges, 2007).

Since the focus was on managers, my two fellow researchers and I shadowed four managers for two days. To secure researcher triangulation, we switched shadows so that one manager was followed by one researcher one day and by another researcher the next day. A principle of shadowing is not to interact with the subject. In one of the shadowing cases, this was successful, while in the other case, the shadowing turned into a long interview, partly interrupted by meetings. This interview was geared to creating knowledge with the respondent, as described by Kvale et al. (2009). The following day, another researcher shadowed that manager with a, from a shadowing point of view, more satisfactory result.

\subsubsection{Working on the workshop floor}

Participating in the actual work on the workshop floor provides a context that can affect interview question subjects (Kvale and Brinkmann, 2009, Bryman and Bell, 2007). This technique was applied for a week in different parts of the production at Type Co, and was also applied at AstraZeneca. In the case of Type Co, the purpose was to follow the whole value-adding chain from subassembly to finished product, but also to participate in material supply work. The whole factory, apart from the sheet metal department, control wiring subassembly and testing, was covered. At least four hours were spent at each section. Data collection was performed regarding improvement work, leadership and work experiences and work content and culture was observed. The input from the work at the workshop floor to some extent guided questions during the interviews. At AstraZeneca, there was a two-day workshop session based on the same thought: to follow the value stream, collect data and share the employees' situation. 


\subsection{Analysis}

Since qualitative case study analysis must be tailored for each case (Yin, 2003), the cases used in Papers one, three, four, five and six have been analysed using a different analytical strategy for each paper, while the cases used in Paper two have been analysed using only one analytical strategy. The theses' main tool regardless of analytical strategy was pattern matching. This was, in some cases, done using theories as lenses while in other cases the intent was to let the data speak for itself. Most of the analysis was theory-based, with systematic combining also showing the need for new theory (Dubois and Gadde, 2002).

When analysing interviews, it is important to codify the data (Kvale and Brinkmann, 2009). The type of codification used was codification of meaning with the aim to building categories that captured the studied phenomena. In all cases, apart from Paper two and Type Co./Industry, the interviews were transcribed and codified. When reading the transcribed interviews, there was a constant search for material that related to that specific paper's theory in order to build an understanding, but also, in one case, a search for patterns regardless of theory. Feeding the understanding back to the interview improved research quality. In the multiple case studies, there was an initial in-case analysis followed by a cross-case analysis, as recommended by Eisenhardt.

In Paper one, the difference in Lean Production definitions was used as an analytical framework; the practical cases showed a similar division. The starting point of Paper two was access to the results of a survey in which more than 100 companies were questioned on their improvement work, such as what results they had achieved and what resources they had used. The analysis focused on verifying the company's position regarding resources used, and investigating how the improvement work was organised. The analysis of Paper three was based on motivational theory and different actions that managers can take were analysed from a motivational point of view. Paper four's data, collected in 2009, was initially analysed as a search for different phases in AstraZeneca's Lean Production work. A shift of phase was defined as decreased focus on certain kinds of tasks combined with an increased focus on other kinds of tasks. Then, an in-phase analysis followed, based on the 1992 Porras and Robertson framework. Paper five used theory regarding culture, group dynamics, motivation and change management to understand the development of the case companies' SISs. Paper six used the four different managerial processes by Yukl (1997) as an analytical framework.

There are several alternatives when it comes to analysis and use of theories. This dissertation combined using established theory within the SIS area to analyse data with using theory from other areas such as group dynamics or motivational theory. Using different theoretical perspectives gives opportunities for increased understanding.

\subsection{Research quality}

In quantitative research, the main determinants for research quality are validity and reliability, validity being the extent to which the investigation covers its intended 
parameters and reliability referring to the degree to which results can be replicated by other researchers (Yin, 2003). In a qualitative study aimed at building new theory, there are no measurements; therefore, validity becomes problematic (Bryman and Bell, 2007).

Reliability is also problematic in a qualitative setting as it is based on a reality from which a researcher equipped with a certain set of questions can derive specific knowledge (Andersson, 1979). This is definitely not always the case; in one study where a colleague and I alternated shadowing a specific manager, one day by me and one day by my colleague, there were major differences regarding interaction and thought exchange. While one of the days was rather unsuccessful from a shadowing perspective, it provided rich information material; thus, the two days provided different information and could have led to different conclusions, depending on the importance of the surplus information.

In another case, an interview developed into a three-hour session with some elements of therapy. The next day the respondent showed up and said that she felt better. The information provided during this interview was very valuable and cast light upon new aspects of the case since different events were confirmed by other individuals. It is questionable whether another researcher would have gotten the same information. The last example illustrates that the reliability is rather low, but, as argued earlier, this might be more of a problem regarding the concept of reliability vis-à-vis the research. The problems with using reliability and validity in non-positivistic research is further highlighted by Hirschman (1986), who introduced the concepts of credibility, transferability, dependability and conformability as alternatives (Hirschman, 1986, Bryman and Bell, 2007).

Credibility is the extent to which the researcher's view is consistent with his or her subject's view. One method for increasing credibility is to arrange subject feedback seminars (Hirschman, 1986, Bryman and Bell, 2007). This was done in all cases apart from those in Paper two, which was the first paper written. These feedback sessions have on several occasions resulted in increased understanding or strategy changes.

Transferability is the extent to which the observed phenomena can fit into divergent interpretive contexts (Hirschman, 1986, Bryman and Bell, 2007); therefore, it is not possible to transfer interpretations to an undefined context. This is fully in line with what is argued herein: that SISs are, to a great extent, context-specific. Therefore, it is not possible to apply strategies and actions that have proven successful in one case into another context without analysing how they will be affected.

The third concept is dependability; that is, the extent to which the findings are stable and consistent. In positivistic research, the equivalent of dependability is reliability (Hirschman, 1986, Bryman and Bell, 2007), which is achieved through improving instruments; in humanistic research, the researcher is the instrument. By using several instruments, that is, researchers, dependability can be increased. Since both data collection and interpretation are affected by the individual performing the task, there will 
be deviation between different researchers; however, if the interpretations point in completely different directions, there is a need for clarification (Hirschman, 1986). All data apart from that collected from Type Co./Industry were analysed by other researchers.

The final concept is conformability, which is analogous to neutrality and objectivity in positivistic research. However, in humanistic research, the researcher and his or her knowledge and experience is supposed to affect the interpretation even though it should be free from prejudice and judgement (Hirschman, 1986). To improve conformability, outside auditors can be used. This concept is fulfilled by journals' double-blind review process (although, to some extent, the blind review has a positivistic approach since knowledge about the researcher is lacking). 


\section{Chapter 4 Description of papers}

In this chapter, the most important results from each paper are described. The purpose of the chapter is to provide a basic familiarity with each paper. This dissertation consists of six papers, each of which investigates a different aspect of SIS. All the papers in this dissertation concern improvement systems, albeit from different perspectives. Paper one, "Two views on Lean Production: Alternative interpretations of the Toyota production system”, highlights conceptual understanding and how outcomes depend to a great extent on interpretations, it is important to emphasise choosing and adapting a concept in line with both the organisation's values and situation. This will, among other things, increase employee motivation (Vroom, 1964).

The problems associated with concept change are shown in Paper two, "Continuous improvement put into practice - Alternative approaches to getting a successful quality programme". One finding is that organisations that frequently change concept will get limited results regardless of the amount of resources used. Since this paper focuses on improvement work organisation and how it can affect both success and to some extent sustainability, the first two papers can therefore be said to address collectively strategies and tactics. Paper three "Management initiation of continuous improvement from a motivational perspective" is also on the tactical/operational level and takes the different kinds of organisation of improvement systems described in Paper two a bit further by describing actions and behaviour that enhance continuous organisational improvement.

In Paper four, "From Successful to Sustainable Lean Production - The Case of a Lean Prize Award Winner", the level of detail is increased through studying a Swedish Leanprize winner in its journey from a fledgling to an experienced Lean company. This paper maps the different stages, identifies changes in leadership and culture and investigates supporting structure for improvement work and employee attitude changes. In Paper five, "Changing the Thinking and Behaviour of an individual When Implementing Lean Production", the level of detail is further increased and based on the findings in Paper four. Thus, the level of detail is increased throughout the papers ranging from concept 
interpretation to forces surrounding the individual. Paper six, "The daily work of Lean leaders - lessons from manufacturing and healthcare”, moves away from models and focuses more on the actual acts of managers and how they contribute to an SIS. There is also a discussion of the relation between improvement system maturity and the demands on leaders/managers. Paper six is thus more practical.

\subsection{Two views on Lean Production}

In Paper one "Two views on Lean Production: Alternative interpretations of the Toyota production system", the starting point is the differences among Lean definitions. The existence of the two views has caused problems both for practitioners and academics (Modig et al., 2011) in terms of what Lean is and, consequently, how it is to be implemented. The Paper consists of an investigation of Lean's development combined with empirical data from four organisations that had a reputation for successful Lean implementations. The more technically system focused Lean is termed SM-Lean due to its close resemblance with Scientific Management while the Lean that incorporates the social system as well is termed H-Lean, where H stands for "human". The investigation of the development of Lean shows that the differences can stem from the problems associated with American scientists' translation of Lean Production from a Japanese context (Modig and Åhlström, 2011).

Three of the four organisations addressed in the empirical segment practiced H-Lean while one practiced SM-Lean. The main differences between the two types occur within the areas of organizing the improvement work, the role of management, empowerment, changes in spare-time behaviour and sustainability. In H-Lean organisations, employees have the main responsibility for performing the improvements and the improvement work is integrated with other tasks. Thus, improvements become part of the daily work and not something that are performed on special occasions.

Between 50 and 75 percent of the employees in H-Lean organisations have changed their spare-time behaviour through the application of Lean thinking in their everyday life, like using $5 \mathrm{~S}$ in the garage or kanban in the spence. This is a strong indication of changed thinking. H-Lean also shows a higher degree of sustainability than SM-Lean, which is caused, at least to some extent, by the changes in thinking. Apart from the differences in focus, each organisation also followed their own path toward Lean. All H-Lean paths contain an iteration between technical system focus and social system focus. In all cases, the social system achieves attention first, before the focus moves to the technical system and then back to the social system and so forth. As a result, changes are not linear, but can better be described as circular and affect the technical and the social systems in turn. This paper was written solely by Swartling and is currently under review at an academic journal. 


\subsection{Continuous improvement put into practice}

Paper two, "Continuous improvement put into practice - Alternative approaches to getting a successful quality programme" contributes to the existing body of knowledge about what distinguishes effective continuous improvement (CI) and explains some of the mechanisms that create a successful quality programme. The paper starts with defining CI and its components and details different CI organising modes. There are four different alternatives: parallel, integrated, coordinated or project. In the parallel mode, CI work is performed by specialists and not integrated with ordinary work. In the integrated mode, $\mathrm{CI}$ is part of employees' ordinary tasks. A coordinated mode overlaps parallel and integrated work with more complicated cross-functional work performed in parallel, and simpler CI work integrated with ordinary work. Finally, there is the project mode where there is both a starting point and a stopping point.

The empirical data is collected from seven companies, with subsequent analysis showing that improvement work organised as projects is weak regardless of the amount of resources used. Integrating improvement work and ordinary work and combining them with a focus on learning results in high improvement levels and low resource consumption. Parallel expert organisation can also give substantial improvements, but will use more resources than the integrated approach and will not give the motivational effects that integrated improvement work potentially does. The empirical data was collected jointly by Swartling and Olausson, with the main part of the writing done by Swartling. This paper is published in International Journal of Quality and Service Sciences.

\subsection{Motivational issues when initiating CI}

In Paper three, "Management initiation of continuous improvement from a motivational perspective", improvement system initiations are investigated from a motivational viewpoint as almost all improvement initiatives are introduced by management, which decides about goals and resources. However, improvement initiative success depends on all employees participating and contributing (Kaye and Anderson, 1999), this is especially important for $\mathrm{CI}$, where employees are the key drivers in generating and implementing ideas (Liker, 2004). Subsequently there is a need for a transition from management initiation to the stage where the CI system is taken over by employees. This transition is crucial if the CI system is to achieve wide participation and persist over time (Bateman, 2005). However this transition often fails. Success or failure depends on actions of management but what do management need to consider when initiating an SIS? How can management actions make employees more willing to participate in SIS work?

There are two main areas where management actions have an impact regarding SIS, that is, respect for people and how the improvement system is organised. Respect for people is mainly based on classical motivational theory. Different actions both within respect for people and how the CI system is organised are analysed from a motivational perspective. 
One requirement is trust between employees and management. For employees to at all consider working with CI there has to be trust. If there is mistrust, i.e. any appearance that management will use the improvements to reduce the workforce or that the CI work will only result in increased workload the motivation will be low or absent. Trust, thus is a basic foundation for building an SIS. Even in the presence of trust there remains the question, "what's in it for me?". There needs to be a satisfying answer to that question. A change in leadership style toward a more coaching style so that managers offer support rather than give orders will be favourable from a motivational point of view.

The described actions will make the employees more positive toward CI. If the employees start to work with CI, the next management task is to help them succeed. Training and education plays a vital role, but all competence-enhancing activities need to be based on problems or opportunities within the organisation since this makes the employees more motivated to participate. Improvement work organised along the processes within the organisation also gives both an increased task identity (Hackman and Oldham, 1980) and reduces the risk that different departments or professional groups will only look to their interests. Two other aspects of CI work organisation is communication and visualisation; how these are designed has motivational impact. The paper was written by Swartling and Poksinska and is published in the Journal of Applied Economics and Business Research.

\subsection{From successful to sustainable Lean}

In Paper four, "From Successful to Sustainable Lean Production - The Case of a Lean Prize Award Winner", provides a deeper look into the mechanisms that turn an initially successful implementation of Lean Production into a sustainable improvement programme.

AstraZeneca and its Turbuhalers production unit was identified as a case of a sustainable Lean Production; an in-depth case study of their operations was subsequently conducted. A successful improvement system requires senior management commitment and involvement, a focus on people, strategic goal integration and creating a CI culture. In our view, there is a distinction between successful and sustainable improvements that is not clearly evident in earlier research.

Empirical data was collected during autumn 2009 from the AstraZeneca Turbuhaler facility. The AstraZeneca improvement system has been both successful and sustainable. Factors that contribute (1) only to success, (2) to both success and sustainability, and (3) only to sustainability of the improvement programme have been identified. Understanding the different roles of success factors and sustainability provides insights on why improvement programmes often fail. Empirical data for this paper was collected jointly, by Swartling and Poksinska. Writing was done jointly by Swartling, Poksinska and Witell with Poksinska taking the main responsibility. 


\subsection{Changing thinking and behaviour}

In Paper five, "Changing the thinking and behaviour of an individual when implementing Lean Production", the individual is put in focus. If a prerequisite for an SIS is that the employees change their thinking and behaviour then it is interesting to find out what forces that affect the individuals thinking and behaviour. The paper studies how the different contextual factors and groups surrounding an individual influence her/his thinking and behaviour in the creation of an improvement system. Creating improvement systems are often studied as acts of managers or change agents (Armenakis et al., 1999). Prescriptions are given on how those who manage changes should act in order to succeed (Kettinger and Grover, 1995, Kotter, 1995, Buller, 1988, Beer and Nohria, 2000). Creating an SIS is often perceived as controllable and predictable (Sveningsson and Sörgärde, 2007). However, the reality surrounding the improvement system makes it more complex and the outcomes are influenced by all manner of alliances between various social, economic, political and cultural forces (Pettigrew et al., 2001). Empirical data for this multiple case study was collected from three organisations that have been working with Lean as an improvement strategy. Apart from acts of managers and change agents, context, history and process have been suggested (Pettigrew et al., 2001) as other areas to take into account during the development of an SIS but even that is not enough. The forces applied from culture (Dahlgaard and Dahlgaard-Park, 2006) and different groups have a strong influence on how the individual acts and thinks and these forces need to be considered as well. The groups found in the cases were political group, professional group, work group and improvement group. In the studied cases, high influence from the political group, professional group and work group increased resistance to change, while high influence from the improvement group reduced change resistance.

Empirical data for this paper was collected mostly by Swartling, but support both in data collection as well as writing was given by Poksinska.

\subsection{The daily work of Lean leaders}

Paper six, "The daily work of Lean leaders - lessons from manufacturing and healthcare", contributes to a better understanding of Lean organisation leadership and managerial practices by investigating five Lean organisations. The key factor in creating and changing organisational culture is leadership (Schein, 2010). Mann (2005) stated that the primary reason for the failure of many Lean initiatives might be the inability to change leadership practices. Lean Production requires a different approach to management and leadership, a change in the way a manager acts, interacts and communicates with workers and makes decisions (Liker, 2004, Hines et al., 2008, Mann, 2005).

A part of Lean also addresses a four-stage model that leaders ought to follow: 1) Commit to Self-Development, 2) Coach and Develop Others, 3) Support Daily Kaizen, and 4) Create Vision and Align Goals. This model is compared to generic leadership theory and shows great similarities with transformational leadership. The analytic framework is the 
four managerial processes defined by Yukl (1997): 1) developing and maintaining relationships, 2) getting and giving information, 3) making decisions, and 4) influencing people. The leadership changes that came with Lean affected all of these processes with leaders becoming much more focused on developing and maintaining relationships. In addition, the information flow was altered to become bi-directional, with decisions to a greater extent being made by the employees as a result of their empowerment. Influencing employees toward Lean philosophy and culture was a prime task for the managers. If the supporting management structure was strong, the demands for transformational leadership behaviour decreased. Empirical data for this paper was collected jointly, mostly by Swartling and Poksinska, but also to some extent by Drotz. Writing was done jointly by Swartling, Poksinska and Drotz with Poksinska taking the main responsibility. This paper is published in Total Quality Management \& Business Excellence. 


\section{Chapter 5 Findings}

In the findings, the papers are aggregated to form a more complete picture on why it is difficult to build SISs. The phases within building an SIS and the mechanisms that can be used within those phases are identified and described.

In a Lean SIS, employees are tasked with finding and implementing improvement opportunities. The employees are working within the system to be improved and thus have a good first-hand understanding of it and what possible improvements exist. However, in order to find and realise improvement potential, employees have to have both the competence and the willingness to perform this kind of work. Although the employees have the main responsibility when the SIS is running, with management in a more coaching role, the roles are switched when the system is to be initiated. While the employees are the prime force behind sustaining the improvement system, they have a more modest role in its initiation; it is the management setting the improvement direction, distributing resources and organising improvement efforts. Somewhere there needs to be a transition of initiative from management to employees; without this transition, there will be no SIS based on wide employee participation. It is thus vital that management has transition in mind when initiating the improvement system. If the transition takes place or not depends, as will be discussed later, of the combination of a number of factors. Many of these factors are possible to influence during the initiation, but are difficult to adjust later.

Since a transition is highly context-dependent, it is a gamble to move an improvement system that has worked well in one organisation into another organisation (Hughes, 2006). It is thus not possible to give any generic step-by-step solutions or critical success factors. The classical improvement programmes did not cover transition. Taylor (1911) focused solely on management acts; since employees were not part of the improvement system, there was no need for transition. Roethlisberger and Dickson (1939) excluded management and instead observed the effects of work condition and social interaction changes. Within Lean Production, Liker (2006) recommended a series of expert-led 
workshops as the implementation tool. The question of transition is not the focus in any of these improvement programs. Thus, neither of the pioneers was concerned with the whole process from management initiation to an SIS and there is still a lack of knowledge concerning the mechanisms that create an SIS. The most widely spread change concepts are step-by-step descriptions of how management and/or change agents should act. They do not problematise concerning history, context or change situation process (Pettigrew and Whipp, 1993). The lack of adaption to the particular situation making them difficult from a sustained change perspective. Many of the concepts (Lewin, 1951, Kotter, 1995) do have a phase where the changes become the norm; however, new norm creation is totally dependent on actions during the previous phases. Despite the apparent flaws, they do add systematic thinking to change processes.

In the AstraZeneca case, there were four different phases: orientation-preparationactivity-sustain (Poksinska et al., 2011). In the other cases, these phases were not as clear; from Paper one, it can be seen that different organisations follow different routes. Although the routes were different it is possible to find a pattern. The change of perspective is vital. Although there is a connection between actions and achievements, this is far from linear and actions are interpreted by individuals in a context. One action in organisation $\mathrm{X}$ will give result alpha, while the same action in organisation $\mathrm{Y}$ might give result beta. All case organisations that achieved an SIS started with an initiation phase then continued with a transition phase and finally focused on sustainability. The phases to some extent overlap, but there are different focuses within the phases. From each phase, there is an output that needs to be in place before work on the next phase can accelerate. The outputs from the phases are the following:

- Initiation: The employees think that the improvement system will be beneficial for them as individuals and groups.

- Transition: The employees have changed their thinking and behaviour.

- Sustaining: The employee's increase in competence is aligned with further increased responsibility and the improvement system is continuously improved.

Whether or not these demands are fulfilled rests on a number of different factors that will be scrutinised in the following parts.

\subsection{Initiation}

An improvement system contains numerous context-specific parameters that influence how it is perceived. The perception is made in a specific context where there is a history concerning improvement systems, culture and specific management types. The improvement system itself needs to be aligned with the context and also contain content in line with the organisation's needs. Finally, there are different kinds of groups and individuals with different properties. All these factors affect improvement system initiation, as will be described in this chapter. 


\subsubsection{Context}

\subsubsection{Improvement system history}

The results of earlier improvement systems come to mind when a new one is being discussed, automatically forming an historical viewpoint (Pettigrew and Whipp, 1993). There is often scepticism toward improvement systems and management's hidden motives. Is there trust or distrust between management and employees? Have there been recent strikes or lockouts, or is there a cooperative spirit between management, employees, and the union? If there is a risk of being fired, this has clear negative effects; security is threatened (Liker, 2004) and context dissatisfaction is created (Hackman and Oldham, 1980).

When the Municipality announced that they were going to work with improvements, the instinctive reaction from the employees was "who is going to be fired?", but in this case, the purpose was not staff reduction, but instead being able to spend more time with the elderly.In the AstraZeneca case, there had been several attempts to build improvement systems, but they all faded away. Management saw the need to communicate that it was different this time. A history of faded improvement systems potentially raises expectations that the same thing will happen again: there is an expression BOHICA (bend over here it comes again) that describes how many employees respond to a series of faded improvement systems. An expressed long-term commitment (Liker, 2004, Repenning, 2002) and a constancy of scope (Deming, 1991) should be present during all SIS development stages.

\subsubsection{Culture}

Organisational culture is shaped by management (Schein, 2010), though hysteresis ensures management acts of today will affect future culture. Although Schein includes subculture and micro-culture in his theory, in this dissertation, they will be interpreted as norms from a group dynamic perspective. When discussing culture in this section, the focus will be on organisational culture.

From a sustainable improvement perspective, and especially regarding initiation, employees must trust their managers and think that the improvement system is beneficial for them or their group. Trust is closely connected to earlier management or change agents acts (Ford et al., 2008) and, thus, a part of both improvement system history and culture. How management treats a crisis can be seen as an interesting opportunity to observe values in action.

The Municipality worked for several years to define and establish basic values as one way of building a common culture. The values are frequently used as guidance for behaviour, presented during employment interviews and used as a guide when choosing 
improvement methods and tools. Thus, there was limited need for changed thinking during the transition process since this had already taken place.

At Care Centre 1, the managers focused their improvement goals on workplace stress and that it should be fun to go to work, clearly emphasising employee needs. There was previously a culture where each professional group stuck to their interests with the doctors the most powerful. There was subsequently a cultural change which, to some extent, started with the cross-professional improvement groups. Now the expressed value is to make things as easy as possible for all involved.

At AstraZeneca, there was also a culture change where power that used to be in the quality department was transferred to the employees. The thinking was changed to reflect the idea that the task of all managers and support units was to make things as easy as possible for the employees.

In the AstraZeneca case, there were layoffs during the improvements, but, at the same time, no one was fired. This might seem confusing, but there were voluntary packages that individuals could apply for consisting of 12 months' pay without any work requirement and SEK 100,000 cash in hand. All who left did so voluntarily. At Type Co, there were several layoffs mainly due to lack of orders, but there were no voluntary packages and those fired needed to depend on the unemployment fund without any company obligation. From an SIS transition point of view, culture should be modified so that obstacles to changed thinking and employee behaviour are removed. In the successful cases, this has been done as a combination of a more coaching management style and gradual employee empowerment. Culture is a vital aspect of the whole SIS journey.

\subsubsection{Management}

Management's role during SIS design varies, but it is primarily one of transformational leadership (Poksinska et al., 2013). During the initiation phase, the main focus is on interacting with individuals and seeing them as such to develop and maintain relationships. If management listens to and is influenced by its employees, it can influence them in turn.

In all cases, management showed the direction, but not necessarily the strategy. At the Municipality, management's role was less direct and their improvement work was extremely bottom-up. The employees defined the problem, worked out the solutions and implemented them.

The quality department provided support regarding different tools and methods, such as value-stream mapping and $5 \mathrm{~S}$. Coming up with an idea, investigating it, and implementing it prompts an overview of the whole improvement process and thus increases motivation (Hackman and Oldham, 1980).

Though managers, as mentioned earlier, drive the initiation phase, there are certain mechanisms that limit their choices if they want to achieve an SIS. First, they need to 
make the improvement system a common cause for both management and employees. Three different ways of achieving this have been observed: the first is to demonstrate on several occasions over a long period the problems it sees and, thus, convince employees that the planned improvement system is needed and beneficial. In the AstraZeneca case, several mobilising days included playing different instructive games, followed by discussions on how the games' findings could be applied in their own context. Alternative two is to share employee experiences, participate in their work and gain firsthand experience regarding problems. This was done at Care Centre 1, where the managers also had an operative role. The third alternative is to let the employees find problems, with management providing support regarding suitable tools and methods. This was done in the Municipality, where the initiation, investigation and implementation were done by the employees. The opposite circumstance, where management is knowledgeable of Lean, but the further you move down the hierarchy, the less knowledge exists, with employees told to do certain things like $5 \mathrm{~S}$ or Kanban without knowing why, was observed at Type Co.

\subsubsection{Reward systems}

Earlier improvement systems, like suggestion boxes, promoted the notion that good ideas were to be rewarded with extra money. When working with Lean or TQM improvements, this thinking no longer applies: employees are expected both to produce and improve without any extra monetary reward (Liker, 2004). This shift has some associated problems: instead of rewards they are used to, individuals receive attention, influence, increased autonomy and similar soft rewards. The value of this kind of reward is difficult to estimate in advance and thus probably does not compare favourably, which, according to Vroom (1964), will affect motivation. The difficult part is making groups and individuals appreciate things that they have not yet experienced; once that occurs, they will have less value uncertainty. During the initiation phase, it is important to consider the alignment between the reward system and the improvement system to come.

At AstraZeneca, there was a combination of both reward systems: while there was a substantial individual bonus, its size was based on improvement work participation. At the same time, employees were strongly challenged to submit improvement ideas, with the majority of those being quickly realised, even if the improvements were small or absent. The idea was to show that improvement suggestions were valued. In a later stage, the demands for the ideas were increased and some were not realised as they only constituted a change, not an improvement.

In all other cases there were no monetary rewards, only different kinds of intrinsic rewards. 


\subsubsection{Improvement system properties}

\subsubsection{Adaption of improvement programme to context}

A crucial SIS point is that the change direction needs to have a sturdy connection to the organisation's actual situation since a weak connection will make the transition phase more difficult. Toyota only tried to solve their own problems (Modig and Åhlström, 2011); copying their methods and tools might work if your organisation has the same problems that they have, but otherwise it is doubtful. To copy methods and tools and find out that they do not solve the problems will affect credibility and motivation (Vroom, 1964).

In Scientific Management, there was no intention to democratise problems; it was management's responsibility to ensure that the employees worked in the most scientifically efficient way. In the Hawthorne experiment, management control was withdrawn and changes such as meals, breaks and working hours were introduced (Dickson and Roethlisberger, 1939). This resembles the Municipality to the extent that improvements were employee-driven; however, in the Hawthorne experiment there was no management support for improvements.

If there is an improvement system motivation gap, there are two options: the first is to enhance motivation, for instance, by revealing ways that the system affects the individual. The other option is to change the content so that is more appealing for the employees who, thus, become more motivated to contribute to improvement work.

As mentioned, the improvement systems in the cases had different foci; that is, each organisation needs to create its own improvement system based on type of problems and context.

In one healthcare unit where we acted as a sounding board (not included in any of the papers), it was initially decided to implement capacity planning since it had worked well in another healthcare unit. However, when we investigated the unit's problems, it was revealed that capacity planning would not solve them. This healthcare unit is far from unique, and it is common that methods that have worked in one organisation are transferred to another organisation (Hughes, 2006).

\subsubsection{The content aspect}

In many cases, improvement system content is more or less taken for granted. Dale (2007) described a framework for implementing TQM, and Liker (2006) described implementing Lean Production. Why should tool choice come before problem investigation? Wouldn't it make more sense to establish the problem first and then choose a suitable tool regardless of the improvement programme?

Improvement system content has a great influence on how it is perceived. The content is where to focus attention, for instance regarding quality or waste; it also addresses 
methods and tools. There were two cases of improved efficiency, one that was sustainable and one that was not. In the sustainable case, there were leadership style changes to a more coaching role and a focus on health safety and environment; these were lacking in the unsustainable case. Using Lewin's 1951 force field analysis, there is a need for the improvement system content to make a bigger contribution then deduction. Employees of organisations that have SISs see the system as contributing to their work: "We improve for ourselves", "we have more time to care", "the improvement system makes work less stressful". It is important that the content is aligned with both the problems experienced as well as motivational theory. There needs to be an attractive mix of increased competence, management support, increased responsibility, autonomy, achievement, being seen as an individual by management, and being able to affect things at the workplace or similar motivating factors. As a result, improvement system content is highly context-dependent.

\subsubsection{Improvement system organisation}

Improvement system organisation affects employee perceptions and thus is a part of the improvement system properties. There are three main organisational possibilities: projects, a parallel organisation or integration within the organisation (Swartling et al., 2011). Projects are difficult from a transfer point of view since they are frequently of the "solutions looking for problems" type and thus lose credibility when reaching the individual operator.

A parallel organisation staffed by experts is also problematic since it does not contribute to the employee-embedded skills needed for a successful transfer. Such an organisation can educate employees in the tools and methods needed to solve identified problems or realise improvement opportunities, but when performing the actual improvements there will not be a spread of participation.

\subsubsection{The individual and group}

An individual employee might be more or less motivated for a specific improvement activity. As described earlier, there are many factors that influence whether or not the activity is viewed positively. Among the first questions posed is "what's in it for me/us?" There is almost always improvement system scepticism; at AstraZeneca, the supervisors spent a lot of production area time answering questions and quenching rumours. If they stayed in their office, there was a line of irritated employees at their door at the afternoon. How the individual perceives the suggested improvement system depends on their growth-need strength (GNS) (Hackman and Oldham, 1980), as well as if they think that the suggested system will solve the problems experienced (Vroom, 1964).

From the cases, there was a variety of answers to the "what's in it for me?" question. At AstraZeneca, there was a combination of carrot and stick. The carrot part consisted of a focus on improving health, safety and the environment, combined with mobilising days that showed the benefits of a new kind of thinking and a less uneven workload. The stick 
part was that it was mandatory to participate and management would continue this work no matter what. Care Centre 1 focused on employee needs, such as less stress and more fun at work, while the Municipality offered employees the opportunity of solving their own problems; however, in the Type Co/Industry case, there were no clear answers and many operators saw the aim of the improvement system as making them work harder.

As described earlier, groups form norms that guide acceptable behaviour, but that also have a tendency to self-perpetuate. It is thus important to reduce the power of, for instance, political and professional groups. At Care Centre 1, there was a need to reduce the professional groups' power with the solution was to form cross-professional groups responsible for different Care Centre processes. At Type Co./Industry, there was a strong political group whose power remained unthreatened.

The goal of the first phase is that employees have a positive response to the improvement system. There should also be satisfying answers to the questions "What's in it for me/us?" As can be seen from the cases, this state can be achieved in many different ways.

\subsection{Transition}

As earlier mentioned there need to be a transition from management initiation to employees running the improvement system. In order to achieve a transition from management initiation to employees running the improvement system, employees need to think that improving is part of their regular work. Managers also need to change to a more coaching leadership style, empowering the employees.

\subsubsection{Thinking versus behaviour}

In an SIS, employees regard improvement as a natural part of their work; in its absence, it is incumbent on managers to effect a suitable transition both in employee thinking and employee behaviour. Porras (1992), and Beer et al. (1990) argued that employee behaviour is shaped by organisational roles; therefore, employees should be put into a new organisational context. Attitudes, ideas and beliefs are secondary and shaped by recurring patterns of behavioural interactions (Beer et al., 1990). From an organisational culture viewpoint, behaviour is derivative and determined by thoughts, attitudes and feelings, and by situational contingencies (Schein, 2010). There is a school of thought that advocates the need for iteration between behaviour and thinking. The studied cases show iteration examples, as in AstraZeneca; behaviour changes only, as in Type Co; and focus on thinking pattern changes that guide changes in behaviour, as in the Municipality.

Since finding improvement opportunities will be a question of changing employee thinking and behaviour, one of the more important questions will be "What makes an individual change their thinking?" The answer to that question is complex since thought changes do not appear in a vacuum, but rather in a specific setting (Schein, 2010, Larsson and Vinberg, 2010) where management, culture and Group dynamics, as well as individual properties, have an influence. 
There are obviously different views on the relationship between thinking and behaviour, but it can be argued that changes in each mutually affect one another (Beer et al., 1990, Hughes, 2006, Schein, 2010). The potential problems with focusing on only one of the parameters is shown in Figure 3.

\begin{tabular}{c|c|c|}
\multicolumn{2}{c}{ No } & \multicolumn{1}{c}{$\begin{array}{l}\text { Changes in } \\
\text { Thinking }\end{array}$} \\
\cline { 1 - 2 } Yes & $\begin{array}{l}\text { Two alternatives; either } \\
\text { unreflecting change in } \\
\text { behaviour or changes in } \\
\text { behaviour will affect } \\
\text { thinking }\end{array}$ & $\begin{array}{l}\text { Changes in both behaviour and thinking } \\
\text { creates a mutually reinforcing loop }\end{array}$ \\
$\begin{array}{c}\text { Changes in } \\
\text { Behaviour }\end{array}$ & $\begin{array}{l}\text { No change takes place } \\
\text { No }\end{array}$ & $\begin{array}{l}\text { Two alternatives; changes in thinking will } \\
\text { disintegrate and have no impact or changes } \\
\text { in thinking will affect behaviour }\end{array}$ \\
\hline
\end{tabular}

Figure 3 The connections between changes in thinking and behaviour

Changed employee thinking can be divided into two different types: the first is thinking that improvement work is part of their job, and the second is thinking in line with the improvement programme. In the Municipality case, the first thinking change type was already in place, so there was only a need for changes toward Lean thinking. In all the other cases, there was a need for changed employee thinking, both regarding work role and the improvement system. In both AstraZeneca and at Care Centre 1, the first and second thinking change types took place, while at Type Co, there were limited work role changes: running the improvement system was not considered part of the job and Lean was seen as a paced production line. One indicator that the employees really had changed their thinking was that between 50 and 75 percent of those interviewed at AstraZeneca, the Municipality and Care centre 1 altered their spare time behaviour to be more in line with Lean thinking.

\subsubsection{Management behaviour and endurance}

Values and norms are difficult to change and, when changed, even more difficult to roll back; changes often take years (Repenning, 2002), or decades (Dale et al., 2007). When change strategies fluctuate, a fatigue will cause the improvements to be small, regardless of the resources used (Swartling and Olausson, 2011). As mentioned earlier, both Deming (1991) and Liker (2004) stressed long-term commitment. Management needs to show commitment, both in words and in action, and to persuade employees that this time changes are long term.

During the transition phase, AstraZeneca, Care Centre 1 and the Municipality leaders adopted a more coaching leadership style to encourage the employees to work within the 
improvement system and, at the same time, give them the possibility of developing new skills, some of which used to be managerial skills. The requirements for new skills will contribute to increased motivation (Hackman and Oldham, 1980). As described earlier, the culture is formed by management actions, but with a hysteresis. The changes in management behaviour described above influence culture and make it more supportive toward the employees or, as described by the third hierarchical level manager at AstraZeneca: "our job is to make things as easy as possible for the operators".

\subsubsection{Forces affecting the individual}

There are strong reasons for putting the individual, where the changes in thinking and behaviour are to appear, at the centre of attention. In some change management research (Kotter, 1995, Porras and Robertson, 1992), there has been a focus on change agents' and managers' actions. However, Since SISs imply individual-level changes, manager and change agent actions are only one of several forces and it is more fruitful to focus on the affected object. Data from Type Co./Industry, the Municipality and Care Centre 1 revealed the following sources of forces affecting the individual:

- Situation of the organisation

- Culture

- Political group

- Professional group

- Work group

- Improvement group

- Leadership

Not all sources are active in the same organisation, although situation and leadership were identified as influential in all three organisations. A crisis situation is an influential changeresistance reduction factor as it gives a sense of urgency, as stressed by Kotter (1995). The culture differed widely among the organisations. In the case of the Municipality, the organisational culture had a positive impact; in the Care Centre 1 case, the creation of cross-competence improvement groups had a positive impact on reducing the influence of the professional groups. "There are big groups like, for instance, doctors that will not change unless they see that it is to their advantage, but once they are onboard it works excellent" (manager Care centre 1). While employees change as individuals, resistance is to some extent formed in groups.

Another part of the forces affecting the individual is organisation politics. Different groups within the company want to protect their own interests and will obstruct certain changes. Politics is always a factor within improvement systems (Liker, 2006) particularly given a lack of transparency regarding decision making. In the Type Co./Industry case, the office and workshop "us and them" division drove inter-group blame. Since the improvement groups were connected to each department, they did not reduce the officeworkshop tension. On top of that, there were political intrigues with false rumours being 
spread concerning the improvement system leader; thus, different work groups were reluctant to see beyond their own interests, while at Care Centre 1, the improvement groups diminished the negative influence from professional groups.

In the Municipality, one anti-change individual were deliberately chosen to participate in each improvement groups, since participating in the improvement work would make them see the benefits. The influencing forces can be seen in Figure 4.

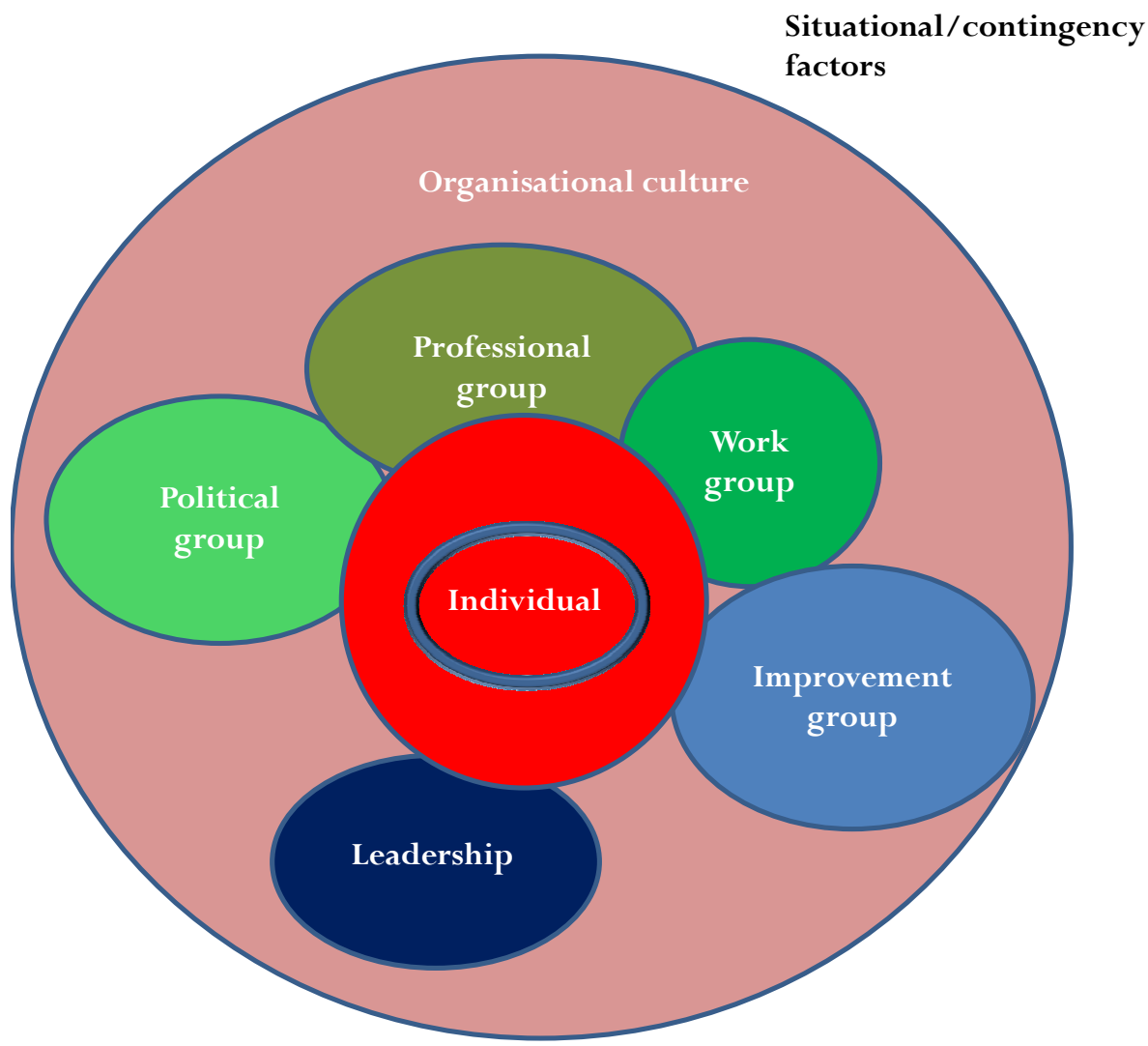

Figure 4 Forces affecting the individual in an improvement system situation

\subsubsection{The role of systems, methods and tools}

There are two generic types of tools and methods depending on their purpose. One type is focused on finding underlying causes, and the other is for solving problems. The methods are often, but not always, used in the sequence "find and solve". The causefinding type provides alternative ways of structuring data, while the problem-solving type provides solution systems. From a changed thinking and behaviour perspective, the causefinding type provides an understanding of the problem and the problem-solving type provides a practical result. Both results are beneficial from a motivation point of view: 
since understanding will influence task identity (Hackman and Oldham, 1980), and solutions give a feeling of achievement and provide feedback (Herzberg, 1966, Hackman and Oldham, 1980). However, it is important to note that learning a method does not provide motivation: it is using it that has an impact.

Teaching methods that are in fashion, but do not solve the problems experienced or understood by the employees will have a de-motivating effect ("do managers understand nothing of us employees?"). Tools and methods can thus have both a motivating and demotivating effect depending on their alignment with the problems experienced. "I have played the Lean game and participated in Lean courses but there is nothing I can use in my daily work" (Doctor my Care centre). Competence built through solving problems often increases the demand for learning new methods and tools depending on the employee's GNS (Hackman and Oldham, 1980).

In the transition phase, the improvement system is built using different kinds of tools and creating a systematic approach to running the improvement system; at the same time, the social system is effected through employee empowerment (Hackman and Oldham, 1980). From a systems viewpoint, there is a clear iteration between the social system, where employees change their thinking, and the more technical part of the improvement system, where changes in behaviour become visible. The technical methods will, when combined with changes in thinking, increase employees' problem-solving and potential improvement-finding competence. The knowledge and skill increase will positively affect motivation (Hackman and Oldham, 1980).

Changed thinking and behaviour allows employees to regard improvement as an integrated part of their work, builds competence and prompts responsibility for running the improvement system. However, with increased competence, there is a need for expanding the area where this can be applied. This is what happens in the next phase.

\subsection{Sustaining}

Sustaining is not a state, but rather a process in which managers and change agents do have an important role not as creators but instead as facilitators (Shani et al., 2002). The task of change agents and managers is to create the right conditions for sustainability (Hackman, 2012). The right conditions for sustaining are created during the initiation and transition phases as described in 5.1 and 5.2. However, there is a new challenge when the introduction pace for new methods and tools slows down. The employees will no longer to the same extent be challenged by learning new methods or tools but they are used to increase their competence and develop their knowledge. There need to be new challenges for the employees. These challenges can appear in a variety of areas depending on the knowledge and interest of the employee. The type and difficulty of the challenge need to be adapted to the individual, while some individuals might want to take over major parts of the supervisors' tasks, others might settle for just continuing working within the SIS. The challenge needs to be adapted to the individual's GNS (Hackman and Oldham, 1980). Although GNS has been considered a static individual capacity, there are 
indications that it increases when performing successful improvement work (Cheser, 1998). There is a positive spiral where successful improvement work increases the need for further challenges.

Both AstraZeneca and Care Centre 1 provided new employee roles. At AstraZeneca, it could be running the operations or having a special quality or improvement system responsibility, while at Care Centre 1, improvement groups performed different managerial tasks, such as how to solve mass vaccinations and respond to changed demands within healthcare. At the Municipality, employees participating in the improvement groups were given the mandate of introducing their findings. At Type Co./Industry, there were no changes in responsibility apart from that employees were responsible for cleaning and organising their own workplace.

During the research shadowing at AstraZeneca, production equipment broke down and maintenance personnel were called in. However, the operator that was running the equipment had a better understanding of the control cabinet than the maintenance personnel, which is not common. Apart from managerial roles to grow into, there were obviously technical specialist roles as well.

Apart from the question of continued employee challenges, there are also qualities of the improvement system itself that need to be developed in order to make it sustainable. One aspect is to make the system independent of key individuals. There are numerous examples of improvement systems that fade away when one or several key managers or change agents quit.

Successfully transferring improvement system responsibility reduces dependence on certain managers or change agents. Another contribution would be to make the improvement system more structured. Having a set of short meetings every morning to visualise performance and set problem-solving activities, etc., ensures there are no initiatives needed to maintain the improvement system. This is a change from individuals supporting the improvement system to the improvement system supporting the individuals.

When there is a strong improvement system structure, the need for key individuals disappears and more or less all managers/change agents can be replaced as long as the new managers/change agents work within the improvement system. At AstraZeneca between 2009 and 2011, there were only two managers of eight that had not been exchanged. The two individuals were both first-line managers and could hardly be seen as key individuals for the improvement system work. Apparently, AstraZeneca managed to dispense with any dependence on key individuals. One reason for this is the observed high level of employee pull; another reason is the structured improvement system with a high visibility level to all involved.

One factor that contributes both during the transition and sustain phase is achievements within the improvement system. Achievement is a strong motivator (Herzberg, 1966) 
and will improve motivation. There is a positive spiral where achievements create increased motivation for improvement work which in turn result in more achievements and thus more motivation (Repenning,2002). 


\section{Chapter 6 Conclusions and contribution}

The purpose of this dissertation is to contribute to understanding of the process of creating an SIS and the mechanisms within this process. The research questions are:

What is the process for creating an SIS?

- What mechanisms influence the sustainability of improvement systems

- How do the different mechanisms influence the sustainability of improvement systems?

Based on the discussions in the beginning of chapter 5 , it can be concluded that there is a generic process for implementing sustainable improvement systems. This process consists of the phases initiation-transition-sustain. Each phase has a certain state that need to be reached before the next phase can start. The state can be reached in a number of ways, activities are less important than actual achievement.

Based on this process there are different mechanisms during different phases of initiationtransition-sustain. The mechanisms are used for achieving the different states. The mechanism itself is a case-dependent combination of several factors. The factors interact and create conditions where the mechanisms operate and in the successful cases contribute to achieving the states. The first state which is the outcome of the first phase is that the employees regard the changes as beneficial for them.

The second state is that the employees have changed their thinking and behaviour and the third state is that the improvement system is sustainable. In Figure 5, the phases are shown as boxes and the states appear between the phases. 


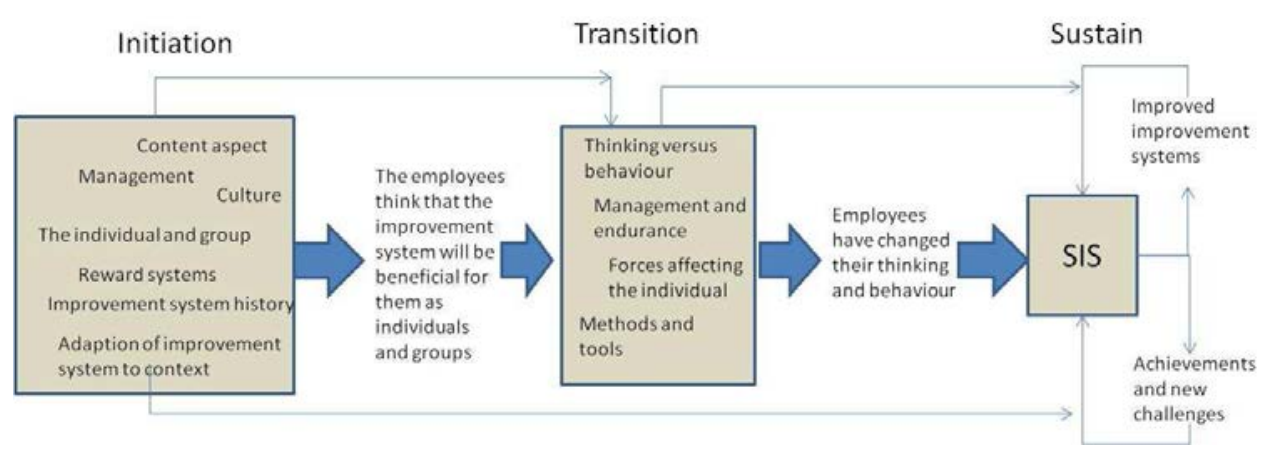

Figure 5 The process of implementing an SIS

\subsection{Initiation phase mechanism}

The initiation phase mechanism output is to have employees think that the improvement system will be beneficial for them as individuals and groups. There are a number of factors as shown in Figure 5, and more deeply analysed in chapter 5.1, that impact whether the outcome is reached or not. As shown by the cases, there are a multitude of different combinations of the factors and it is not possible to find one specific cause for success or failure but rather to investigate the level of the different factors and probably work with some of them to create a condition more favourable for the mechanism to achieve the first state. It is a matter of tipping the scales and preferably removing factors from the negative scale pan since increased pressure for a change often creates increased resistance (Lewin, 1951). As shown in Figure 5, the factors also directly affect the SIS; for instance, even if the employees think that the improvement system will be beneficial a lack of adaption of improvement system to context or lack of change in management style will endanger the sustainability of the improvement system. The factors have different properties concerning the possibility to change. Improvement system history is at a given point in time unchangeable and culture takes a lot of time to influence. On the other hand the content of the improvement system and its adaption to context is decided during the development of the improvement system so these factors will be decided upon within the improvement system work. Changing the reward system is far easier than changing culture; however, some changes in the reward system will affect culture. From a management point of view, there is a need to investigate the state of all factors and based on this design an improvement system that the employees will consider as favourable. If this is not possible, they either need to change one or several obstructing factors or simply decide not to try to implement an improvement system.

\subsection{Transition phase mechanism}

The outcome of the initiation phase is that the employees think that the improvement system will be beneficial for them as individuals and groups. There has been very limited or no operational improvement work. What is to be achieved in the transition phase is 
that the employees operate the improvement system accompanied by changes both in behaviour and thinking. The behavioural changes are that improvement work is to be an integrated part of the work and changes in thinking are that the employees need to incorporate the thoughts of the improvement system into their own mindset to be able to contribute more actively to the improvement work. It is a matter of developing individuals into willing and competent improvers running the improvement system. The foundation for willing has been built during the initiation part, this need to be maintained and the competence need to be developed.

Individuals and groups are expected to change their thinking and behaviour. If they choose to do so is to a great extent a question of motivational theory and group dynamics. The transition receivers consist of individuals; though they are part of the context, there are some specific properties based in motivational theory and group dynamics that apply. The reason for excluding these areas from the initiation is that they are not shared within the whole organisation, but are more connected to employees. At first, there is a history among the receivers as well. In many organisations, change work is seen as an extra task and rewarded separately using a suggestion box system (Boer et al., 2000). In Lean, TQM, Kaizen or similar improvement systems, employees are expected to work with improvements as a part of their ordinary work without any monetary rewards. The rewards are more intangible, such as having influence, seeing suggestions being realised and having a greater understanding of your contribution to the whole picture.

The transition is not done by companies or departments, but rather occurs on a group or individual level. If the individual or group does not see any answer to "what's in it for me?" questions, or believes the answer implies negative outcomes, the willingness to contribute to the improvement system will be lacking. The individual is also subject to group dynamics that can have the same effect: even if the individual is positive toward the improvement system, the system will have problems if the group has another opinion.

The prime factor for building competence is training and education in appropriate methods and tools and using them. Competence does not occur from just learning a set of tools, but is created when using the tool for solving a problem. From this point of view, it is preferable to start with finding the problems and then learning the appropriate tools for solving the problem. A solved problem will be an achievement and positively affects motivation. The increased competence is preferably accompanied by increased responsibility so that the employees can be more self-propelled and take a greater responsibility for running the improvement system.

An important factor to maintaining and developing willingness is empowerment and changes in management style. When managers no longer solve the problems, but instead coach and support the employees in their problem solving, the responsibility for the improvement work is transferred to employees. The increased empowerment, increased competence in combination with feedback from managers and improved understanding of their role in both the improvement and production/service-providing system in combination with the increased growth need strength that successful continuous 
improvement work provides (Cheser, 1998) enhances almost every factor in the Hackman (1980) motivational model.

\subsection{Sustain mechanism}

Even if there has been a successful transfer and the improvement system is run by the employees, this does not necessarily imply an SIS. In order to have an SIS, there is a need for employees to be able to fulfil their growth need strength and thus develop their knowledge and skill and face new challenges. In practice, this is achieved through empowerment and giving employees further responsibility, often of a managerial nature, in combination with additional training. As shown in Figure 5, there is also a need to enhance the improvement system towards being more systematic, better alignment with strategic goals and/or better use of resources.

There are many kinds of improvement programmes and far from all of them require employee participation: in, for instance, Six Sigma, improvement projects are run by especially dedicated employees with different kinds of belts, which limits the need for the participation of other employees. From a transition perspective, this is simpler and if great difficulties are expected concerning the transition phase, Six Sigma might be preferred at the cost of fewer individuals actively participating in the improvements. The transition in itself puts high demands on management since they hand over the running and, to some extent, the control of the improvement system to the employees and shoulder a more coaching role. Therefore, transition resistance might come not only from the employees, but from managers as well. Using a transition perspective enhances understanding what needs to be achieved in order to succeed, but not necessarily what needs to be done.

\subsection{Contribution}

The contribution of this dissertation mainly concerns the area of employee participation in improvement systems but also how managers and leaders need to act and think in order to create an SIS. Within the area of quality management, everyone's participation in the improvement work is vital (Deming, 1991). There has however been limited research on how to achieve and sustain participation. The existing frameworks for implementing TQM have often been step-by-step descriptions (Yusof and Aspinwall, 2000), although at least one framework has been more context-dependent (Dale et al., 2007). Unfortunately, turning to classical change management theories do not provide solutions since these often focus on acts by managers and change agents in a top-down implementation.

When implementing an improvement system top-down, there is an assumption that employees will do as they are told or eventually think as they are told. If the expected change in behaviour does not appear this is due to lack of pressure and power, applying more pressure will result in the expected outcome (Burnes, 2009). Any parent who has had teenagers will doubt if more power will change behaviour and thinking. Without 
changes in behaviour and thinking there will be no SIS. Apart from the top-down problem, there is also a problem with presumptions concerning that their own improvement programme is the solution to all problems. Both Dale (2007) and Liker (2006) describe how their solution to the problem, TQM, and Lean Production should be implemented. The issue is that they do so without any diagnosis of the problems that need to be solved; thus, alignment is lost. A parallel can be drawn to administrating a cure without any diagnosis; although this is sometimes done, it is hardly the appropriate way.

As Burnes (2009) argued, it is time to return to Lewinian values that emphasise how employees need to choose to change behaviour and thinking. However, the process of unfreeze-change-refreeze (Lewin, 1951) although sufficient 66 years ago, is not suitable since within an SIS there will be continuous changes and thus no refreeze.

So neither the models for building sustainable improvement systems within the quality area, nor Lean Production, nor change management theories based on use of power or the change models of Lewin, are sufficient to build an SIS. This constitutes the main contribution of this dissertation since SISs are scrutinised not from the perspective of what managers or change agents need to do, but what needs to be achieved. Using this perspective, a rather simple three-step model emerges. The first state is that the employees need to think that the improvement system will be beneficial to them as individuals or groups; the second state is a transition of the responsibility for running the improvement system from management to the employees; and the third state is a further development of the competence and empowerment of the employees.

The model might seem deceivingly simple, but the states are difficult to achieve. The first state that the employees see the improvement system as beneficial for them as individuals or groups depends on number of factors such as trust between management and employees (Ford et al., 2008), alignment between the content of the improvement system and problems within the organisation (Beer, 2003), but also on factors related to motivational theory (Hackman and Oldham, 1980) and group dynamics (Wheelan, 1994). All these factors are system-specific; hence, these factors form a mechanism. Here is the second contribution within the dissertation, that is that classical theory within motivational theory and to some extent group dynamics is used to analyse the forces that influence an individual when initiating an improvement system. An understanding of these forces and their contribution to the mechanism can aid management during their design of the improvement system or lead to an understanding that it is at the moment not possible to implement an SIS. The force field analysis was introduced by Lewin (1947), but within this dissertation there is an adaption to the work life of today.

The second state, the transition of the responsibility for running the improvement system from management to the employees, is also problematic to achieve. Employees decide to take improvement system responsibility as individuals. One by one they engage more deeply in the improvement activities. If it was a difficult task for managers to make the employees see the improvement system as beneficial, it does not get easier. In order to 
have employees take greater responsibility, managers need to adopt a more coaching style (Stewart and Manz, 1995) and focus more on developing and supporting their employees. Apart from changing management style, training and education, empowerment within the areas of increased competence, feedback, highlighting achievements, and new challenges will ease the transition. All of these areas are part of classical motivational theory, in particular the Hackman (1980) motivational model. During the second phase, the employees need to change their view on their work tasks so that their work is also to improve. This changed view is accompanied by changes in behaviour. Regarding changes in thinking, there is another finding within this dissertation. It contributes with a benchmark that indicates whether or not the employees have changed their thinking: if the employees have changed their spare time behaviour to be more in line with the thought of the improvement programme, then there is a change in thinking.

The third state, a further development of the competence and empowerment of the employees, is fairly straightforward if the demands from the other phases have been fulfilled. To sustain the improvement system, there need to be more challenges then just to operate it; after a number of years there is not much left to improve (Heller, 1998). These new challenges are often in the form of what used to be managerial tasks. Employees are trained in and execute tasks such as running the operations, problem solving, or take a special responsibility within Lean, quality or maintenance of production equipment or maybe further development of improvement system itself.

The final contribution is focused more on practitioners. The different factors that management needs to consider during the phases are described in such a level of detail that managers and change agents can understand which these factors are and how they contribute or cause problems with an SIS. This hopefully will help one or several stubborn consultants, managers or change agents out there.

\subsection{Future research}

This dissertation instigates a change in how to regard SISs. There is limited use in looking for success factors or only looking at the acts of managers. What management can do is to create SIS conditions. The sustainability of improvement systems depends on the thinking and behaviour of those who are to operate the improvement system, that is, the individuals within the specific organisation. How they behave and think will be specific to the organisation or part of organisation, meaning there will be intrinsic mechanisms for implementing an SIS. Some of the factors that form these mechanisms have been described in this dissertation, but there is almost certainly a need for further research how other factors affect the mechanisms in other organisations. And finally it is my belief that the research on SISs would benefit from focusing more on the employees and the forces that affect them. 


\section{References}

ANDERSSON, S. 1979. Positivism kontra hermeneutik, Göteborg, Korpen.

ARMENAKIS, A. A. \& BEDEIAN, A. G. 1999. Organizational change: A review of theory and research in the 1990s. Journal of Management, 25, 293-315.

ARMENAKIS, A. A., HARRIS, S. G. \& FIELD, H. S. 1999. Paradigms in organizational change: Change agent and change target perspectives. In: T.GOLEMBIEWSKI, R. (ed.) Handbook of Organizational Behavior New York: Marcel Dekker.

BATEMAN, N. 2005. Sustainability: The elusive element of process improvement. International Journal of Operations \& Production Management, 25, 261-276.

BEER, M. 2003. Why total quality management programs do not persist: The role of management quality and implications for leading a TQM transformation*. Decision Sciences, 34, 623-642.

BEER, M., EISENSTAT, R. A. \& SPECTOR, B. 1990. Why change programs don't produce change. Harvard Business Review, 68, 158-166.

BEER, M. \& NOHRIA, N. 2000. Cracking the code of change. Harvard Business Review, 78, 133-141.

BERGMAN, B. \& KLEFSJÖ, B. 2010. Quality from Customer Needs to Customer Satisfaction, Lund, Studentlitteratur.

BOER, H., BERGER, A., CHAPMAN, R. \& GERTSEN, F. 2000. CI changes: From suggestion box to organizational learning. Continuous Improvement in Europe and Australia, Burlington, Ashgate.

BRYMAN, A. \& BELL, E. 2007. Business research methods, Oxford, Oxford University Press.

BRÄNNMARK, M. \& BENN, S. 2012. A proposed model for evaluating the sustainability of continuous change programmes. Journal of Change Management, 12, 231-245.

BUChanAn, D., FITZGerald, L., KeTley, D., GOllop, R., JONES, J. L., LAMONT, S. S., NEATH, A. \& WHITBY, E. 2005. No going back: A review of the literature on sustaining organizational change. International Journal of Management Reviews, 7, 189-205. 
BULLER, P. 1988. For successful strategic change: Blend OD practices with strategic management. Organizational Dynamics, 16, 42-55.

BURNES, B. 2009. Reflections: Ethics and organizational change-time for a return to Lewinian values. Journal of Change Management, 9, 359-381.

CHESER, R. N. 1998. The effect of Japanese Kaizen on employee motivation in US manufacturing. International Journal of Organizational Analysis, 6, 197-217.

CROSBY, P. 1979. Quality is free, New York, McGraw-Hill.

CZARNIAWSKA-JOERGES, B. 2007. Shadowing and other techniques for doing fieldwork in modern societies, Copenhagen, Copenhagen Business School Press.

DAHLGAARD, J. J. \& DAHLGAARD-PARK, S. M. 2006. Lean Production, six sigma quality, TQM and company culture. The TQM Magazine, 18, 263-281.

DALE, B. G., WIELE, T. V. D. \& IWARDEN, J. V. (eds.) 2007. Managing quality, Malden: Blackwell Publishing.

DEMING, W. E. 1991. Out of the Crisis, Cambridge, Cambridge University Press.

DEMING, W. E. 1994. The New Economics for Industry, Government, Education, Cambridge MA, Massachusetts Institute of Technology.

DICKSON, W. J. \& ROETHLISBERGER, F. J. 1939. Management and the worker. Boston: Harvard School.

DU GAY, P. \& VIKKELSØ, S. 2012. Reflections: On the lost specification of 'Change'. Journal of Change Management, 12, 121-143.

DUBOIS, A. \& GADDE, L.-E. 2002. Systematic combining: An abductive approach to case research. Journal of Business Research, 55, 553-560.

EISENHARDT, K. 1989. Building theories from case study research. Academy of Management Review, 14, 532-550.

EISENHARDT, K. M. \& GRAEBNER, M. E. 2007. Theory building from cases: Opportunities and challenges. Academy of Management Journal, 50, 25-32.

ELG, M. 2001. Performance measures and managerial work, Linköping, Univ., Department of Mechanical Engineering.

FEYERABEND, P. 1975. Against method (1975), London, Verso.

FORD, J. D., FORD, L. W. \& D'AMELIO, A. 2008. Resistance to change: The rest of the story. The Academy of Management Review, 33, 362-377.

FRANKFORT-NACHMIAS, C. \& NACHMIAS, D. 2007. Research methods in the social sciences, London, Worth Publishers.

GUMMESSON, E. 1999. Qualitative methods in management research, Thousand Oaks, SAGE Publications, Inc.

HACKMAN, J. R. 2012. From causes to conditions in group research. Journal of Organizational Behavior, 33, 428-444.

HACKMAN, J. R. \& OLDHAM, G. R. 1980. Work redesign, Reading, MA, AddisonWesley

HAMMER, M. \& CHAMPY, J. A. 1993. Reengineering the corporation. A manifesto for business revolution, New York, HarperCollins.

HARARI, O. 1993. Ten reasons why TQM doesn't work. Management Review, 82, 33-38. 
HEDEGAARD HEIN, H. 2012. Motivation: Motivationsteorier och praktisk tillämpning. Malmö: Liber AB.

HELLER, F. 1998. Organizational participation: Myth and reality, Oxford, Oxford University Press.

HERZBERG, F. 1966. Work and the Nature of Man, World Publishing Company Cleveland.

HINES, P., FOUND, P., GRIFFITHS, G. \& HARRISON, R. 2008. Staying Lean: Thriving Not Just Surviving. Cardiff: Lean Enterprise Research Centre.

HIRSCHMAN, E. C. 1986. Humanistic inquiry in marketing research: Philosophy, method, and criteria. Journal of Marketing Research, 23, 237-249.

HOLWEG, M. 2007. The genealogy of Lean Production. Journal of Operations Management, 25, 420-437.

HUGHES, M. 2006. Change Management: A critical perspective, Wimbledon, CIPD Publishing.

HUGHES, M. 2011. Do 70 per cent of all organizational change initiatives really fail? Journal of Change Management, 11, 451-464.

IMAI, M. 1986. Kaizen: The Key to Japan's Competitive Success, New York, McGraw-Hill.

JURAN, J. M. 1989. Juran on Leadership for Quality: An Executive Handbook, New York, The Free Press.

KAYE, M. \& ANDERSON, R. 1999. Continuous improvement: The ten essential criteria. International Journal of Quality \& Reliability Management, 16, 485-506.

KETTINGER, W. \& GROVER, V. 1995. Special section: Toward a theory of business process change management. Journal of Management Information Systems, 12, 9-30.

KIPPENBERGER, T. 1998. Planned change: Kurt Lewin's legacy. The Antidote, 3, 10-12.

KLAUSSNER, S. 2012. Trust and Leadership: Toward an Interactive Perspective. Journal of Change Management, 12, 417-439.

KOTTER, J. P. 1995. Leading Change: Why transformation efforts fail. Harvard Business Review, 73, 59-67.

KRAFCIK, J. 1988. Triumph of the Lean Production System. Sloan Management Review, 30, 41-52.

KUHN, T. S. 1970. The structure of scientific revolutions, 2nd ed, Chicago, University of Chicago Press.

KVALE, S. \& BRINKMANN, S. 2009. Den kvalitativa forskningsintervjun. Lund.

LARSEN, B., PEDERSEN, K. M. \& AAGAARD, P. 2005. Begejstring og distance: Unge videnarbejderes motivation og ledelse, Djøf/Jurist-og Økonomforbundet.

LARSSON, J. \& VINBERG, S. 2010. Leadership behaviour in successful organisations: Universal or situation-dependent? Total Quality Management, 21, 317-334.

LENNÉER-AXELSON, B. \& THYLEFORS, I. 2005. Arbetsgruppens psykologi, Stockholm, Natur och kultur.

LEWIN, K. 1947. Frontiers in group dynamics. Human Relations, 1, 143-153.

LEWIN, K. 1951. Field Theory in Social Science, New York, Harper \& Brothers.

LEWIN, K. \& LEWIN, G. W. 1948. Resolving Social Conflicts: Selected Papers on Groups Dynamics [1935-1946], New York, Harper \& Row. 
LIKER, J. 2004. The Toyota Way: 14 Management Principles from the World's Greatest Manufacturer, New York, McGraw-Hill.

LIKER, J. 2006. The Toyota way fieldbook, New York, McGraw-Hill.

LIKER, J. K. \& CONVIS, G. L. 2011. The Toyota way to lean leadership, McGraw-Hill.

LINDHOLM, I. 2000. Envis konsult vände förlust till vinst [Online]. Available: http://www.nyteknik.se/nyheter/verkstad/verkstadsartiklar/article215447.ec e [Accessed 10062013].

LOFQUIST, E. A. 2011. Doomed to fail: A case study of change implementation collapse in the Norwegian civil aviation industry. Journal of Change Management, 11, 223-243.

MALTÉN, A. 1992. Grupputveckling. Lund: studentlitteratur.

MANN, D. 2005. Creating a Lean Culture: Tools to Sustain Lean Conversions, Portland, Productivity Press.

MASLOW, A. H. 1966. The psychology of science: A reconnaissance, New York, Harper \& Row.

MAYO, E. 1933. The human problems of an industrial organization, New York, McMillan.

MCDONALD, S. 2005. Studying actions in context: A qualitative shadowing method for organizational research. Qualitative Research, 5, 455-473.

MCGREGOR, D. 2006. The human side of enterprise, New York, McGraw-Hill.

MODIG, N. \& ÅHLSTRÖM, P. 2011. Vad är lean?: en guide till kundfokus och flödeseffektivitet, Stockholm, SSE Institute for Research.

NHS Modernisation Agency, 2002. Improvement Leaders'Guide to Sustainability and Spread, Ipswich, Ancient House Printing Group

NÄSLUND, D. 2008. Lean, six sigma and Lean sigma: Fads or real process improvement methods? Business Process Management Journal, 14, 269-287.

OAKLAND, J. 1993. Total Quality Management, Oxford, Heineman Publishing.

PETTIGREW, A. \& WHIPP, R. 1993. Managing change for competitive success, Oxford, Wiley-Blackwell.

PETTIGREW, A. M. 1990. Longitudinal field research on change: Theory and practice. Organization Science, 1, 267-292.

PeTtigreW, A. M., WOODMAN, R. W. \& CAMERON, K. S. 2001. Studying organizational change and development: Challenges for future research. The Academy of Management Journal, 44, 697-713.

POKSINSKA, B., SWARTLING, D. \& DROTZ, E. 2013. The Daily Work of Lean Leaders - lessons from manufacturing and healthcare. Accepted for publication in Total Quality Management \& Business Excellence, scheduled to appear in 24.

POKSINSKA, B., SWARTLING, D. \& WITELL, L. 2011. From Successful to Sustainable Lean Production - The Case of a Lean Prize Award Winner. working paper.

PORRAS, J. I. \& ROBERTSON, P. J. 1992. Organizational Development: Theory, practice, and research. In: DUNNETTE, M. D. \& HOUGH, L. M. (eds.) Handbook of industrial and organizational psychology. 2nd ed. Palo Alto, CA,Consulting Psychologists Press. 
REPENNING, N. 2002. A simulation-based approach to understanding the dynamics of innovation implementation. Organization Science, 109-127.

SCHEIN, E. 2010. Organizational Culture and Leadership, San Francisco, Jossey-Bass.

SHANI, A., FORSLIN, J. \& DOCHERTY, P. 2002. Creating Sustainable Work Systems: Emerging Perspectives and Practice, Routledge, London.

SHEWHART, W. 1931. Economic Control of Quality of manufactured Product, New York, Van Nostrand.

SINCLAIR, J. 2009. Collins COBUILD advanced dictionary, Boston, Heinle Cengage Learning.

SKÖLDBERG, K. 1990. Administrationens poetiska logik: Stilar och stilförändringar i konsten att organisera, Lund, Studentlitteratur.

STEWART, G. L. \& MANZ, C. C. 1995. Leadership for self-managing work teams: A typology and integrative model. Human Relations, 48, 747-770.

SUGIMORI, Y., KUSUNOKI, K., CHO, F. \& UCHIKAWA, S. 1977. Toyota production system and kanban system materialization of just-in-time and respectfor-human system. International Journal of Production Research, 15, 553-564.

SWARTLING, D. \& OLAUSSON, D. 2011. Continuous improvement put into practice: Alternative approaches to get a successful quality program. International Journal of Quality and Service Sciences, 3, 337-351.

SVEDBERG, L. 2003. Gruppsykologi: om grupper, organisationer och ledarskap, Lund, Studentlitteratur.

SVENINGSSON, S. \& SÖRGÄRDE, N. 2007. Organisationsförändring-Från ingenjörskonst till tolkning. Organisationer, ledning och processer. Lund: Studentlitteratur.

TAYLOR, F. W. 1911. The principles of scientific management, New York, Harper \& Row.

TODNEM BY, R. 2005. Organisational change management: A critical review. Journal of Change Management, 5, 369-380.

WEICK, K. E. \& QUINN, R. E. 1999. Organizational change and development. Annual review of psychology, 50, 361-386.

WHEELAN, S. A. 1994. Group processes: A developmental perspective, Boston, Allyn and Bacon.

VROOM, V. H. 1964. Work and motivation, New York, Wiley.

YIN, R. K. 2003. Applications of case study research, London, Sage Publications, Inc.

YUKL, G. 1997. Leadership in organizations, New York, Prentice-Hall.

YUSOF, S. R. M. \& ASPINWALL, E. 2000. Total quality management implementation frameworks: Comparison and review. Total Quality Management, 11, 281-294. 



\section{Appendix I}

Template used for observations during meetings (Elg, 2001)

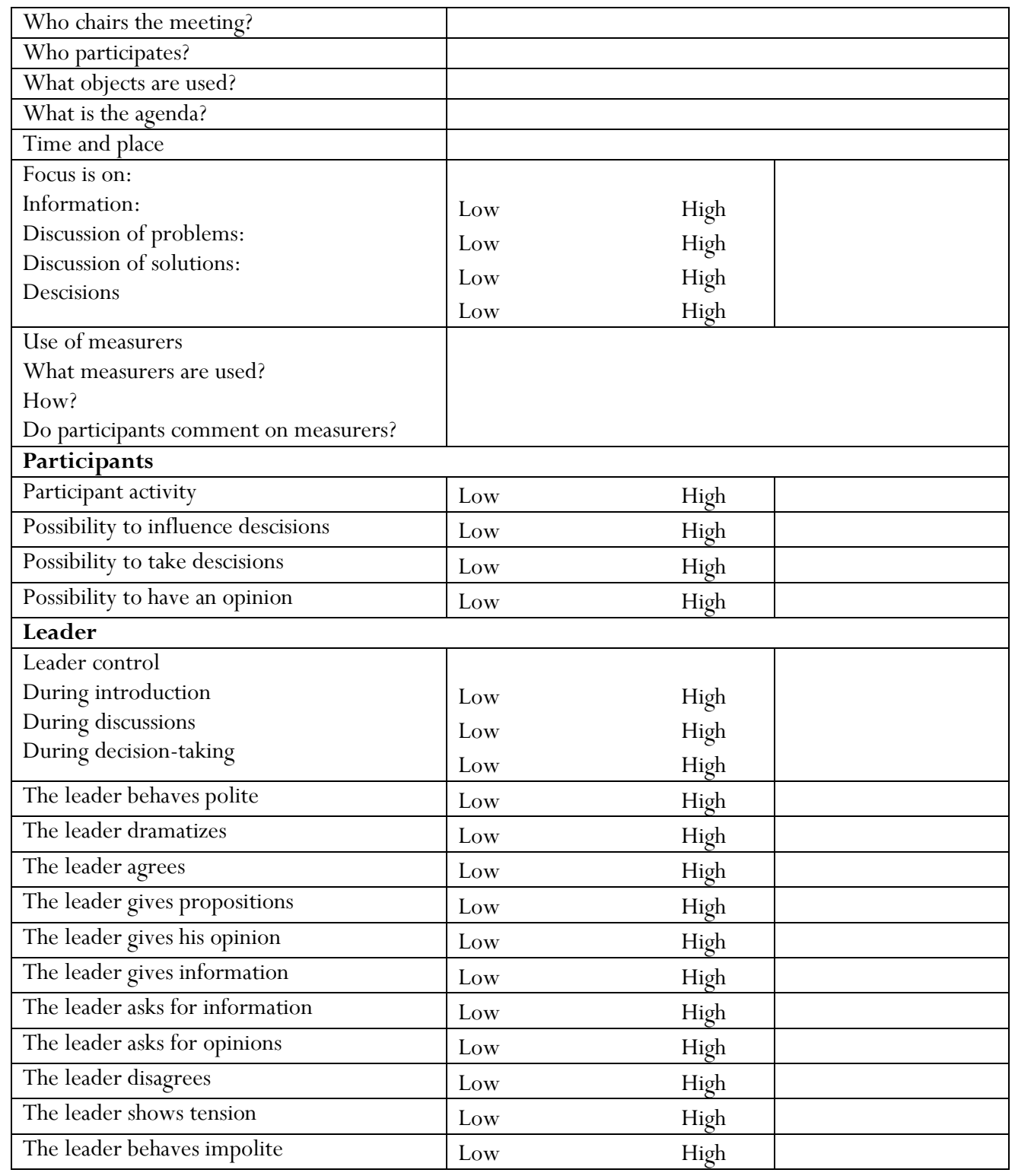




\section{Appended Papers}

The articles associated with this thesis have been removed for copyright reasons. For more details about these see:

http://urn.kb.se/resolve?urn=urn:nbn:se:liu:diva-100165 